\title{
Transcription regulation of the Escherichia coli pcnB gene coding for poly(A) polymerase I: roles of ppGpp, DksA and sigma factors
}

\author{
Beata Nadratowska-Wesołowska • Monika Słomińska-Wojewódzka • \\ Robert Łyżeń • Alicja Węgrzyn • Agnieszka Szalewska-Pałasz • \\ Grzegorz Wegrzyn
}

Received: 19 December 2009 / Accepted: 24 July 2010 / Published online: 12 August 2010

(C) The Author(s) 2010. This article is published with open access at Springerlink.com

\begin{abstract}
Poly(A) polymerase I (PAP I), encoded by the $p c n B$ gene, is a major enzyme responsible for RNA polyadenylation in Escherichia coli, a process involved in the global control of gene expression in this bacterium through influencing the rate of transcript degradation. Recent studies have suggested a complicated regulation of $p c n B$ expression, including a complex promoter region, a control at the level of translation initiation and dependence on bacterial growth rate. In this report, studies on transcription regulation of the $p c n B$ gene are described. Results of in vivo and in vitro experiments indicated that (a) there are three $\sigma^{70}$-dependent (p1, pB, and p2) and two $\sigma^{\mathrm{S}}$-dependent (pS1 and pS2) promoters of the pcnB gene, (b) guanosine tetraphosphate (ppGpp) and DksA directly inhibit transcription from $\mathrm{pB}, \mathrm{pS} 1$ and $\mathrm{pS} 2$, and (c) $\mathrm{pB}$ activity is drastically impaired at the stationary phase of growth. These results indicate that regulation of the $p c n B$ gene transcription is a complex process, which involves several factors acting to ensure precise control of PAP I production. Moreover, inhibition of activities of pS1 and pS2 by ppGpp and DksA suggests that regulation of transcription from promoters requiring alternative $\sigma$ factors by these effectors of the stringent response might occur according to both passive and active models.
\end{abstract}

Communicated by D. Andersson.

B. Nadratowska-Wesołowska $\cdot$ M. Słomińska-Wojewódzka

R. Łyżeń · A. Szalewska-Pałasz · G. Węgrzyn ( $\square)$

Department of Molecular Biology, University of Gdańsk,

Kładki 24, 80-822 Gdańsk, Poland

e-mail: wegrzyn@biotech.univ.gda.pl

\section{A. Węgrzyn}

Laboratory of Molecular Biology (affiliated with the University of Gdańsk), Institute of Biochemistry and Biophysics,

Polish Academy of Sciences, Kładki 24, 80-822 Gdańsk, Poland
Keywords $p c n B$ gene $\cdot$ RNA polyadenylation . Transcription initiation $\cdot$ Sigma factors $\cdot \mathrm{ppGpp} \cdot$ DksA

\section{Introduction}

Activity of bacterial poly(A) polymerase (PAP) was discovered almost 50 years ago (August et al. 1962). This discovery apparently has been overlooked for many years, most probably due to technical problems in demonstrating the presence of poly(A) tails at the ends of short-lived bacterial transcripts. In 1986, Lopilato et al. (1986) reported the presence of the pcnB gene in Escherichia coli. Mutants in this gene significantly influenced copy number of a ColE1-like plasmid pBR322 and its derivatives; thus, the name $p c n B$ (for plasmid copy number) was proposed. Soderbom and Wagner (1998) found effects of the pcnB gene product on degradation of CopA, an antisense RNA involved in the regulation of $\mathrm{R} 1$ plasmid replication. In the meantime, Cao and Sarkar (1992) discovered that the main E. coli PAP I, an enzyme catalyzing RNA polyadenylation at the $3^{\prime}$ end, is encoded by $p c n B$.

In contrast to eukaryotic cells, RNA polyadenylation in bacteria usually leads to its faster degradation (Regnier and Arraiano 2000). This was demonstrated for various specific transcripts, whose half-lives increased significantly in pcnB mutants (O'Hara et al. 1995; Xu and Cohen 1995; Szalewska-Palasz et al. 1998; Blum et al. 1999). Since Mohanty and Kushner (2006) demonstrated that transcripts derived from over $90 \%$ of open reading frames are polyadenylated in exponentially growing cultures of E. coli, it could be suggested that expression of most of bacterial genes may be regulated by polyadenylation-dependent mechanisms. One of the first insights suggesting that this may be the case came from studies on a short transcript of 
bacteriophage $\lambda$, called oop RNA, which demonstrated that oop RNA is polyadenylated by PAP I (Wrobel et al. 1998) and that this modification results in its decreased stability (Szalewska-Palasz et al. 1998). In fact, oop RNA transcripts were shown to be polyadenylated more efficiently in slowly growing cells than in rapidly growing bacteria (Jasiecki and Wegrzyn 2003). Recently, Joanny et al. (2007) demonstrated the poly(A)-dependent regulation of expression of the $g \operatorname{lm} S$ gene in E. coli. Although this regulation appears to be indirect and involves the control of stability of a small regulatory RNA encoded by $\operatorname{glm} Y$ (Reichenbach et al. 2008; Urban and Vogel 2008), these results suggest that efficiency of polyadenylation of certain RNAs may be different under various environmental conditions, indicating an important regulatory role for this reaction (Szalewska-Palasz et al. 2007b). Since some other small regulatory RNAs were shown to be regulated by polyadenylation (Soderbom and Wagner 1998; Szalewska-Palasz et al. 1998; Wrobel et al. 1998; Viegas et al. 2007), one might speculate that this is a major mechanism for controlling gene expression by this process. Furthermore, PAP I is phosphorylated in E. coli, which significantly influences the activity of this enzyme (Jasiecki and Wegrzyn 2006a). PAP I is located in both the cytoplasm and cytoplasmic membrane (Jasiecki and Wegrzyn 2005), thus any factors affecting specific localization of molecules of the $p c n B$ gene product may indirectly cause alterations in expression of other genes.

Since RNA polyadenylation appears to be a global regulatory process in the physiological control of gene expression in bacteria and of replication of extrachromosomal genetic elements (plasmids and phages) (for a review, see Szalewska-Palasz et al. 2007b), discovery of mechanisms controlling production of PAP I is necessary for both understanding these crucial cellular processes and possibly employing them in genetic engineering and biotechnology.

In this light, perhaps surprisingly, regulation of expression of the $p c n B$ gene in $E$. coli is relatively poorly understood. Liu and Parkinson (1989), on the basis of nucleotide sequence analysis, proposed a location of the putative $p c n B$ gene promoter (named pS1 in this report) (Fig. 1). Subsequent studies indicated, however, that this region is located downstream of the actual translation start codon (a noncanonical initiation codon AUU), and another transcription start site (called pB) was discovered by Binns and Masters (2002) (Fig. 1). It appeared that regulation of the $p c n B$ gene expression occurs at the stage of translation initiation (Binns and Masters 2002); however, subsequent studies strongly suggested that transcription control may contribute significantly to the modulation of PAP I production (Jasiecki and Wegrzyn 2003). In fact, it was demonstrated that apart from the pB promoter (Binns and Masters 2002), there are two other promoters, designated p1 and p2 (Fig. 1), that might potentially influence $p c n B$ expression (Jasiecki and Wegrzyn 2006b).

The discovery of the dependence of $p c n B$ expression on bacterial growth rate (Jasiecki and Wegrzyn 2003) might suggest that factors responsible for modulation of transcription in response to various nutritional conditions could be involved in the control of PAP I production. In fact, the stringent control, a bacterial response to amino acid starvation and many other nutritional and environmental stresses, is a global regulatory system that ensures optimal energy usage under unfavorable growth conditions (for recent reviews, see Potrykus and Cashel 2008; Wu and Xie 2009). Molecules recognized as alarmons of this control system have been considered to belong to the most far-reaching effectors, whose major role is an immediate response to

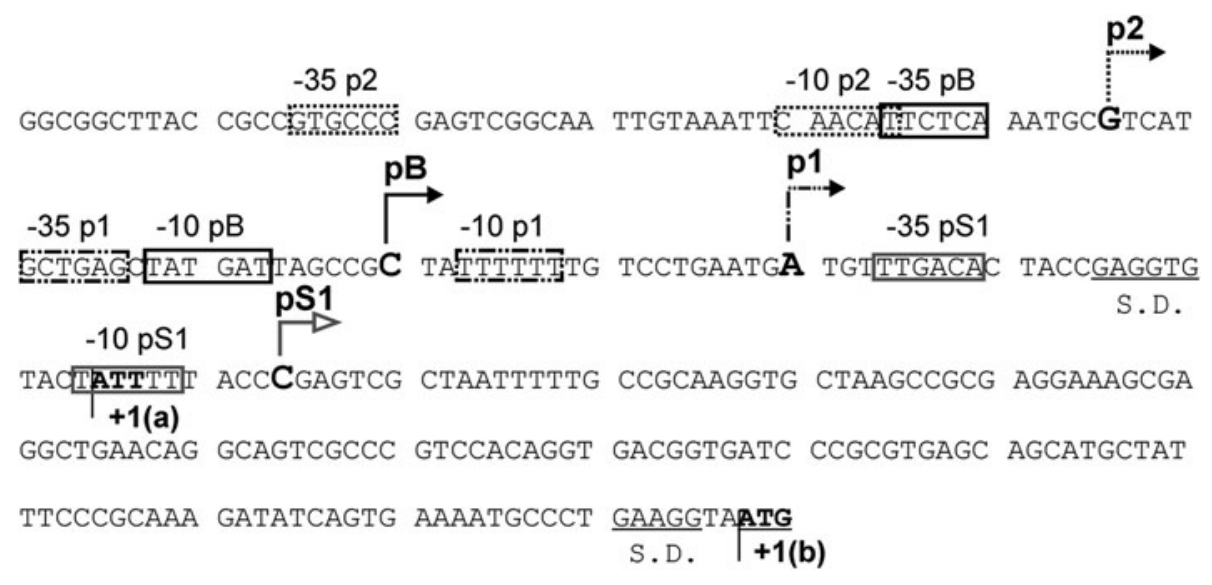

Fig. 1 Nucleotide sequence of the $p c n B$ promoter region. The previously reported (or proposed) transcription start sites from particular promoters (pS1, p1, pB and p2) are marked, with first transcribed nucleotides indicated by large bold letters and arrows showing the

direction of transcription, and -35 and -10 boxes are shown in frames. The Shine-Dalgarno (S.D.) sequences are underlined, and translation initiation codons (ATT and ATG, called +1 (a) and +1 (b), respectively) are indicated by bold letters 
rapidly changing environmental conditions (SzalewskaPalasz et al. 2007b).

There are two major effectors of the stringent response. The first one is a couple of two specific nucleotides, guanosine tetraphosphate (ppGpp) and guanosine pentaphosphate (pppGpp), collectively called (p)ppGpp and rapidly produced in response to variety of physico-chemical and nutritional stresses (for reviews, see Magnusson et al. 2005; Potrykus and Cashel 2008). Since in E. coli ppGpp appears to be more abundant and of higher physiological importance than pppGpp, it is often mentioned as the main stringent response factor. In fact, ppGpp can directly and indirectly regulate expression of variety of genes, important for survival of bacterial cells. It interacts with RNA polymerase (Artsimovitch et al. 2004); however, its exact binding site is still controversial (Vrentas et al. 2008), and it does not introduce any long-lasting conformational alterations to this enzyme (Szalewska-Palasz 2008). The second effector of the stringent response is the DksA protein, which was found as an indispensable factor for ppGpp-mediated effects on ribosomal promoters in vivo (Paul et al. 2004). This protein interacts with RNA polymerase (Perederina et al. 2004), and it was suggested that DksA is a co-factor of the stringent response, enhancing both negative and positive effects of ppGpp on activities of promoters (Paul et al. 2005). Nevertheless, recent reports indicated that roles of ppGpp and DksA in transcription regulation can be independent and even opposing (Magnusson et al. 2007; Lyzen et al. 2009; Merrikh et al. 2009).

The major mechanism of direct ppGpp-mediated transcription regulation was proposed to be a decrease of stability of the promoter-RNA polymerase open complexes (Barker et al. 2001a, b). According to this "active model", promoters that form unstable open complexes are inhibited by ppGpp, while those forming relatively stable complexes might be either stimulated by this nucleotide or insensitive to its presence. Although it was demonstrated that a promoter forming an extremely stable open complex with RNA polymerase can also be negatively regulated by ppGpp both in vivo and in vitro (Potrykus et al. 2002), the model assuming that ppGpp negatively regulates only promoters which form unstable open complexes is generally accepted as the best explanation of impairment of transcription from promoters dependent on the major $\sigma$ factor in E. coli, $\sigma^{70}$ (Srivatsan and Wang 2008).

Another mechanism is proposed to explain effects of ppGpp and DksA on transcription from promoters dependent on alternative $\sigma$ factors. The stringent response effectors have been reported as positive regulators of various promoters recognized by RNA polymerase holoenzymes containing $\sigma$ subunits known to operate under specific environmental or physiological conditions, e.g. $\sigma^{54}\left(\sigma^{\mathrm{N}}\right), \sigma^{38}$ $\left(\sigma^{\mathrm{S}}\right)$ and $\sigma^{24}\left(\sigma^{\mathrm{E}}\right)$ (for a review, see Srivatsan and
Wang 2008). Thus, the "passive model" of ppGpp- and DksA-mediated transcription regulation was proposed (summarized by Srivatsan and Wang 2008). According to this model, stimulation of transcription by ppGpp and DksA under stress conditions is a global consequence of strong negative effects of these effectors on functions of stringently regulated powerful $\sigma^{70}$-dependent promoters. Namely, dramatic down-regulation of transcription from rRNA promoters leads to a significant increase in cellular availability of the core of RNA polymerase for association with alternative $\sigma$ factors. Such a type of regulation has been experimentally supported mainly for $\sigma^{\mathrm{N}}$-dependent promoters (Bernardo et al. 2006, 2009; Szalewska-Palasz et al. 2007a); nevertheless, it is generally accepted for promoters recognized by other alternative $\sigma$ factors, especially in the light of several examples of ppGpp- and DksA-mediated stimulation of transcription from $\sigma^{\mathrm{S}}$-dependent promoters (reviewed by Srivatsan and Wang 2008). On the other hand, $\sigma^{28}$-dependent promoters can be inhibited rather than stimulated by ppGpp and DksA (Lemke et al. 2009), indicating that the above-presented mechanism must be more complicated.

In this report, we present results of our studies on the control of $p c n B$ gene transcription. Our experiments indicated that this control is complex, and involves activities of several factors, including $\sigma^{70}$ and $\sigma^{\mathrm{S}}$ subunits of RNA polymerase, ppGpp and DksA.

\section{Materials and methods}

Bacterial strains, plasmids and growth conditions

E. coli K-12 strain MG1655 (Xiao et al. 1991) and its rpoD800 (Grossman et al. 1983), relA spoT (ppGpp $\left.{ }^{0}\right)$ (Szalewska-Palasz et al. 2007a), dksA::kan (DksA ${ }^{0}$ ) (Kang and Craig 1990) and $\Delta p c n B:: k a n$ (pcnB) (Wrobel et al. 1998) derivatives were used. The relA spoT $d k s A$ (ppGpp ${ }^{0}$ $\mathrm{DksA}^{0}$ ) mutant was constructed by P1vir transduction of the $\Delta d k s A:: t e t$ allele from TE8114 (Brown et al. 2002) into the above-described relA spoT strain. Due to frequent accumulation of suppressor mutations by $\mathrm{ppGpp}^{0}$ and $\mathrm{DksA}^{0}$ strains, bacteria used for experiments were checked for specific phenotypes, like amino acid auxotrophy. The rpoS mutant was constructed by P1vir transduction of the rpoS359::Tn10 from RH90 (Lange and Hengge-Aronis 1991) into MG1655. The rpoS relA spoT strain was constructed by P1vir transduction of rpoS359::Tn10 into ppGpp ${ }^{0}$.

Plasmid pTE103 (Elliott and Geiduschek 1984) was employed. For construction of the plasmid pTE103-F4fanti, a PCR fragment, flanked by primers Fuzja 4 (5'AGA ATT CTC ATT CAT CGC CGT GAT G) and fanti (5'-AGG 
ATC CAA ATT AGC GAC TCG GGT) (Jasiecki and Wegrzyn 2006b) was cloned into BamHI and EcoRI sites of pTE103. This construct was verified by DNA sequencing.

Bacteria were cultured either in LB medium (Sambrook et al. 1989) or in a minimal medium MM (Jasiecki and Wegrzyn 2003) supplemented with various carbon sources: $0.2 \%$ glucose (MMGlu), $0.2 \%$ glycerol (MMGly), $0.6 \%$ sodium succinate (MMSuc) or $0.8 \%$ sodium acetate (MMAce).

Proteins and ppGpp

DksA protein, and RNA polymerase core and various $\sigma$ factors were purified according to previously reported procedures (Gamer et al. 1992; Janaszak et al. 2007; Szalewska-Palasz et al. 2007a). The $\Delta$ HTH-PspF protein was purified as already described (Jovanovic et al. 1999). His-tagged proteins were purified by Ni-affinity chromatography using the BioLogic LP chromatography system (Bio-Rad). ppGpp was purified as described previously (Lyzen et al. 2009). The $\sigma^{\mathrm{S}}$ and $\sigma^{54}$ factors were provided by Dr. Anna Janaszak (Medical University of Gdańsk, Poland). The $\sigma^{\mathrm{E}}$ factor was provided by Ewa Stec (University of Gdańsk, Poland). The E. coli RNA polymerase core, the $\mathrm{E} \sigma^{70}$ holoenzyme, and the DksA protein were purified as described previously by Lyzen et al. (2009).

\section{RNA isolation}

Total RNA was isolated from either exponentially growing bacterial cultures (samples were withdrawn at $A_{575}$ of 0.4 ) or cultures being at the stationary phase (at the beginning of the plateau value of $A_{575}$ in the bacterial growth curve). $10 \mathrm{ml}$ of the culture was centrifuged $(3,000 \mathrm{~g}, 10 \mathrm{~min})$ and RNA was isolated from bacterial cells using the Total RNA kit (A\&A Biotechnology, Gdynia, Poland), according to manufacturer's instruction. Quality of RNA samples was verified electrophoretically and spectrophotometrically.

\section{Primer extension analysis}

The primer extension reactions were performed essentially as described by Janaszak et al. (2007). Briefly, either $50 \mu \mathrm{g}$ of total RNA or $1.5 \mu \mathrm{g}$ of specific $p c n B$ mRNA (generated by in vitro transcription), was mixed with $0.5 \mathrm{pmol}$ of ${ }^{32} \mathrm{P}$-labeled primer. Different primers were used to detect various transcripts: Pr11 (5'-CAG CCT CGC TTT CCT CGC GGC TTA GC) (Jasiecki and Wegrzyn 2006b), pcnTR2 (5'-ACT GTC TCA GTG AAC TCA TCC AT), PS1.rev (5'-TAC ATT ACC TTC AGG GCA TTT TCA), PS2.rev (5'-TTG CTC GAC GCT GAA ATC CTG CCA), OmpA (5'-GCA CCA GTG TAC CAG GTG TTA TC), ompArev (5'-CGG TGA AGG ATT TAA CCG TG), Rsd.1
(5'-ATA TCG TGA CGC CGC TGC TGT TGT), Rsd.rev (5'-TGA CGC GCT CCG TCA GGT TAT CGA G), Fim.B1 (5'-ACT GCG CTC CAT GAA ATA GCC AT), FimB.rev (5'ACG TTG CCA TAC AAA CGC CAT GCT). The mixture was incubated at $85^{\circ} \mathrm{C}$ for $20 \mathrm{~min}$. Following addition of the M-MulLV buffer (Fermentas, Vilnius, Lithuania), a primer was hybridized to RNA at optimal temperature for $60 \mathrm{~min}$. Then, samples were immediately put into ice-bath, and $1 \mu \mathrm{l}$ of $25 \mathrm{mM}$ solution of four dNTPs, $1 \mu$ of RevertAid M-MuLV Reverse Transcriptase (Fermentas) and RNase inhibitor ( 1 unit per $\mu \mathrm{l})$ were added. The reaction was conducted for $60 \mathrm{~min}$ at $42^{\circ} \mathrm{C}$, and stopped by addition of $5 \mu \mathrm{l}$ of the denaturation solution and incubation at $95^{\circ} \mathrm{C}$ for $5 \mathrm{~min}$. The reaction products were separated during electrophoresis in $7 \%$ polyacrylamide gel with $8 \mathrm{M}$ urea; products of the sequencing reaction, with the use of the same primer, were separated in the same gel. The bands were visualized by autoradiography and analyzed using the Quantity One software (Bio-Rad).

Each primer extension experiment was repeated at least three times to assess reproducibility.

In vitro transcription

The in vitro transcription reactions in the presence of ppGpp and/or DksA were performed as described previously (Lyzen et al. 2009), with minor modifications. The following templates were used: for $p c n B$ promoters, plasmid pTE103-F4-fanti; for measurement of $p_{\mathrm{R}}$ activity, pTE103-derived plasmid described by Lyzen et al. (2009); and for studies on $p_{\mathrm{L}}$ activity, plasmid pVI901 (SzalewskaPalasz et al. 2007a). Plasmid DNA was purified by $\mathrm{CsCl}$ density gradient ultracentrifugation and chromatography, using P-30 columns (Bio-Rad). Reactions were conducted in the final volume of $20 \mu \mathrm{l}$, in the transcription buffer (50 mM Tris- $\mathrm{HCl} \mathrm{pH} \mathrm{8,} 10 \mathrm{mM} \mathrm{MgCl} 2,10 \mathrm{mM} \beta$-mercaptoethanol, $150 \mathrm{mM} \mathrm{KCl}, 10 \mu \mathrm{g} / \mathrm{ml} \mathrm{BSA}$ ). Following preliminary experiments, in which optimal concentrations of the template and RNA polymerase were estimated, further experiments were performed with either 4 or $8 \mathrm{nM}$ template and either 30 or $60 \mathrm{nM}$ RNA polymerase holoenzyme. DNA template, RNA polymerase holoenzyme and indicated amounts of ppGpp and/or DksA were incubated for $10 \mathrm{~min}$ at $37^{\circ} \mathrm{C}$. Following addition of a nucleotide mix (to final concentrations: $1 \mathrm{mM}$ ATP, $150 \mu \mathrm{M}$ GTP, $150 \mu \mathrm{M}$ CTP, $15 \mu \mathrm{M}$ UTP, and $\left.1 \mu \mathrm{Ci}\left[\alpha_{-}{ }^{32} \mathrm{P}\right] \mathrm{UTP}, 3,000 \mathrm{Ci} / \mathrm{mmol}\right)$ the mixture was incubated for $12 \mathrm{~min}$ at $37^{\circ} \mathrm{C}$. Then, heparin was added (to $0.1 \mathrm{mg} / \mathrm{ml}$ ) and the incubation was continued for $5 \mathrm{~min}$. The reaction was stopped by addition of $5 \mu \mathrm{l}$ of the denaturation solution (150 mM EDTA, $1.05 \mathrm{M}$ $\mathrm{NaCl}, 7 \mathrm{M}$ urea, $10 \%$ glycerol, $0.0375 \%$ xylene cyanol, $0.0375 \%$ bromophenol blue) and incubation for $5 \mathrm{~min}$ at $95^{\circ} \mathrm{C}$. The reaction products were separated by electrophoresis in a 
$4 \%$ polyacrylamide gel containing $8 \mathrm{M}$ urea in the TBE buffer (Sambrook et al. 1989), and visualized by autoradiography using PhosphorImager (Bio-Rad). The results were quantified densitometrically, employing Quantity One software (Bio-Rad).

In vitro transcription with RNA polymerase holoenzymes containing different $\sigma$ factors: $\sigma^{70}, \sigma^{54}, \sigma^{32}, \sigma^{\mathrm{E}}$ or $\sigma^{\mathrm{S}}\left(\mathrm{E} \sigma^{70}\right.$, $\mathrm{E} \sigma^{54}, \mathrm{E} \sigma^{32}, \mathrm{E} \sigma^{\mathrm{E}}$ or $\mathrm{E} \sigma^{\mathrm{S}}$, respectively) was performed in either the TN buffer $(50 \mathrm{mM}$ Tris- $\mathrm{HCl} \mathrm{pH} 7.5,50 \mathrm{mM}$ $\mathrm{NaCl}, 10 \mathrm{mM} \mathrm{MgCl} 2,1 \mathrm{mM}$ DTT, $0.1 \mathrm{mM}$ EDTA), for $\mathrm{E} \sigma^{70}, \mathrm{E} \sigma^{32}, \mathrm{E} \sigma^{\mathrm{E}}$ and $\mathrm{E} \sigma^{\mathrm{S}}$, or the STA buffer (25 mM Trisacetate $\mathrm{pH} 8.0,8 \mathrm{mM}$ magnesium acetate, $10 \mathrm{mM} \mathrm{KCl}$, $1 \mathrm{mM}$ DTT, 3.5\% PEG 6000), for $\mathrm{E}^{54}$, in the presence of BSA $(100 \mu \mathrm{g} / \mathrm{ml})$ at $37^{\circ} \mathrm{C}$. Before the transcription reactions, $\sigma$ factors were preincubated with the RNA polymerase core enzyme (at molar ratio $1: 4$ ) for $10 \mathrm{~min}$ at $37^{\circ} \mathrm{C}$. The final volume of the reaction samples was $20 \mu$, and contained $8 \mathrm{nM}$ template and $30 \mathrm{nM}$ appropriate RNA polymerase holoenzyme. When $\mathrm{E} \sigma^{54}$ was used, an unspecific activator protein $\triangle \mathrm{HTH}-\mathrm{PspF}$, which can stimulate transcription from $\sigma^{54}$-dependent promoters independently of the DNA sequence (Jovanovic et al. 1999; Janaszak et al. 2007; Wigneshweraraj et al. 2003), was added to $1 \mu \mathrm{M}$ together with $2.5 \mathrm{mM}$ ATP, and incubation was continued for $10 \mathrm{~min}$ (in experiments with other holoenzymes, this stage was omitted). Following addition of nucleotide mixture (as described above), the reaction was conducted for $12 \mathrm{~min}$, and after addition of heparin, for another $5 \mathrm{~min}$. The reaction was stopped by addition of the denaturation solution and separated electrophoretically (as described above).

When the in vitro transcription reaction products were used subsequently for primer extension experiments, unlabeled UTP $(150 \mu \mathrm{M})$ was added instead of $\left[\alpha_{-}{ }^{32} \mathrm{P}\right] \mathrm{UTP}$, and the reaction volume was $100 \mu \mathrm{l}$. Furthermore, the RNA products were purified using the phenol-chloroform extraction and ethanol precipitation (Sambrook et al. 1989).

\section{DNase I footprinting}

Primer Pr10 (5'-AGC ACC TTG CGG CAA AAA TTA GCG AC) (Jasiecki and Wegrzyn 2006b) was end-labeled with $\left[\gamma_{-}{ }^{32} \mathrm{P}\right] \mathrm{ATP}$ and $\mathrm{T} 4$ polynucleotide kinase (Fermentas). DNA fragments were PCR amplified using ${ }^{32} \mathrm{P}$ end-labeled Pr10 primer and unlabeled Przedpen primer (5'-AGA ATC ATG CGC CTG CGT TGC). DNase I footprinting reactions were performed as described previously (Janaszak et al. 2007), in a total volume of $10 \mu$ of the TN buffer (50 mM Tris- $\mathrm{HCl} \mathrm{pH} 7.5,50 \mathrm{mM} \mathrm{NaCl}, 10 \mathrm{mM} \mathrm{MgCl}_{2}$, $1 \mathrm{mM}$ DTT, $0.1 \mathrm{mM}$ EDTA). The labeled DNA fragments (at final concentration of $10 \mathrm{nM}$ ) were incubated for $15 \mathrm{~min}$ at $30^{\circ} \mathrm{C}$ with $\mathrm{E} \sigma^{70}$. DNase I $\left(5 \times 10^{-4}\right.$ units $)$ was added, and after incubation for $1 \mathrm{~min}$ at $37^{\circ} \mathrm{C}$ the reaction was stopped by the addition of EDTA to the final concentration of $50 \mathrm{nM}$, followed by heating for $5 \mathrm{~min}$ at $95^{\circ} \mathrm{C}$ in the urea loading dye. The reaction products were separated by electrophoresis in a $7 \%$ polyacrylamide gel containing $8 \mathrm{M}$ urea, together with the products of DNA sequencing reactions performed using the Pr10 primer and the fmol DNA Cycle Sequencing System (Promega). Each footprinting experiment was repeated at least three times to assess reproducibility.

\section{Results}

$\mathrm{pB}$ is the major promoter of the $p c n B$ gene

Previous studies indicated that there are at least three promoters located upstream of the $p c n B$ coding sequence in E. coli MG1655 genome, called p1, pB and p2 (see Fig. 1; Jasiecki and Wegrzyn 2006b). These promoters were found by primer extension experiments, in which relatively gentle reaction conditions were used (Jasiecki and Wegrzyn 2006b). Such conditions were allowed to obtain comparable strengths of signals from all these promoters. To distinguish actual activities of $\mathrm{p} 1, \mathrm{pB}$ and $\mathrm{p} 2$, we have performed primer extension experiments using significantly more stringent reaction conditions that should cause impairment of signals caused by annealing of the primer to mRNA molecules which occur in low abundance in cells. Relative to the previously reported conditions (Jasiecki and Wegrzyn 2006b), the following changes were made in the protocol used in this work: (a) higher amount of total RNA (50 $\mu \mathrm{g}$ vs. 10-500 ng in the previously reported study) and lower amount of the primer ( 0.5 vs. $15-20 \mathrm{pm}$ ) were used, (b) the denaturation step was longer (20 vs. 5 min) and performed at higher temperature $\left(80\right.$ vs. $\left.65^{\circ} \mathrm{C}\right)$, and (c) the annealing step was added [incubation for $1 \mathrm{~h}$ at the temperature equal to $T_{\mathrm{m}}$ of the primer was introduced rather than starting the primer extension reaction immediately after cooling the mixture (composed of RNA and primer molecules) to $42^{\circ} \mathrm{C}$, and addition of other components of the reaction].

Under these experimental conditions (i.e. under the "stringent" conditions), a highly predominant signal corresponded to the product of the $\mathrm{pB}$ promoter activity (Fig. 2a). The p1- and p2-derived transcripts could also be detected, but only after significantly longer exposure of the electrophoretic gels with labeled reaction products (Fig. 2b). Such a picture of $\mathrm{pB}$ was observed when RNA was isolated from bacteria growing in a rich medium (LB), as well as in a minimal medium (MMGlu), but the weaker promoter signals were detected only in samples from the minimal medium (Fig. 2). This is important as previously described experiments were performed either only in LB (when pB was discovered; Binns and Masters 2002) or only in MMGlu (when $\mathrm{p} 1$ and $\mathrm{p} 2$ were discovered; 
A

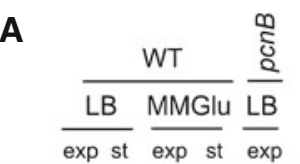

B
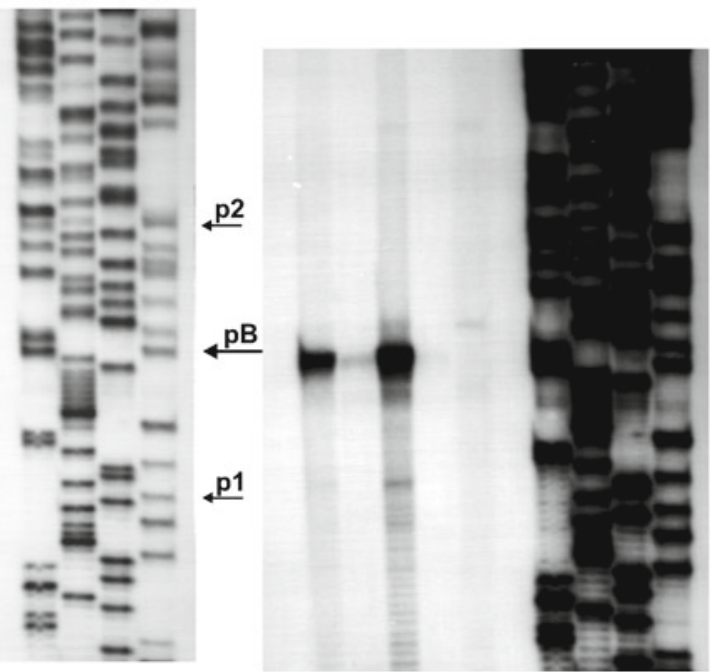

C
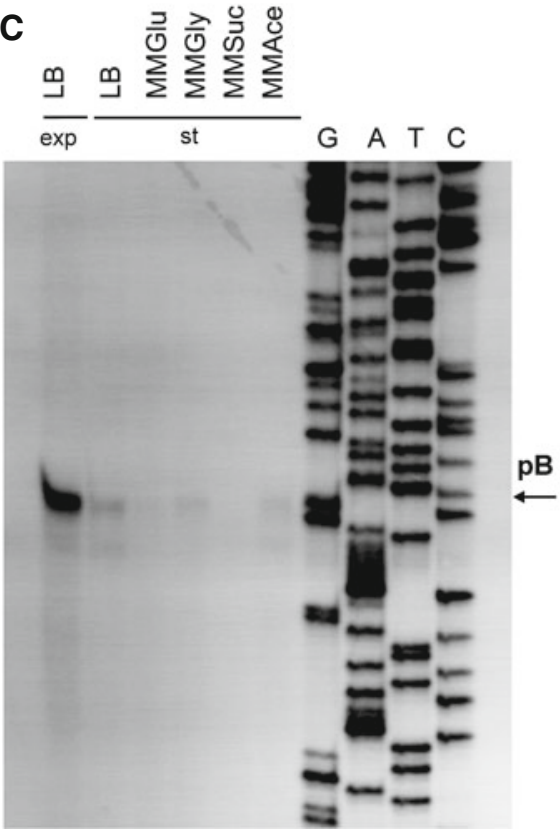

D

$\mathbf{E}$
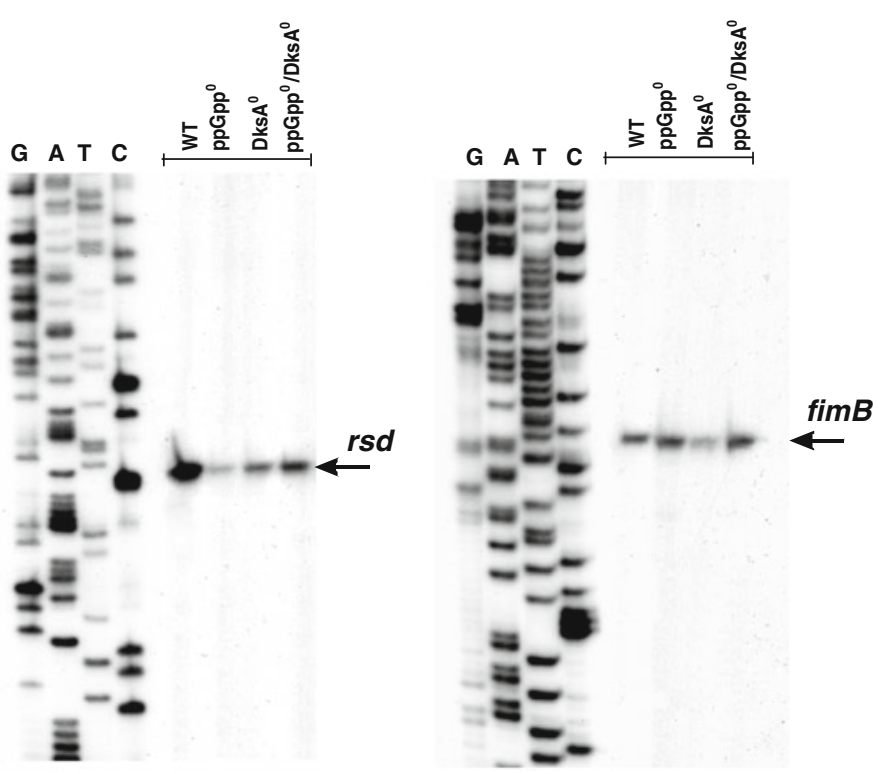

Fig. 2 Transcription from the $p c n B(\mathbf{a}-\mathbf{c}), \quad r s d$ (d) and $f i m B$ (e) promoter regions under various growth conditions of bacterial cultures. In experiments shown in $\mathbf{a}$ and $\mathbf{b}$, wild-type (WT) E. coli or the $p c n B(\Delta p c n B:: k a n)$ mutant was grown in LB or MMGlu medium, to exponential (exp) or stationary (st) phase of growth at $37^{\circ} \mathrm{C}$. Primer extension experiments were performed with primer Pr11 as described in "Materials and methods", and the products of the reactions were separated during polyacrylamide gel electrophoresis, with the products of the sequencing reaction (performed using the same primer) run at the same gel (lanes $G, A, T$ and $C$ ). The position of the products of primer extension reactions, corresponding to transcripts originating from the $\mathrm{pB}$ promoter, is shown in a. Positions previously reported as $\mathrm{p} 1$ and $\mathrm{p} 2$ transcription start sites are also marked by arrows. Apart from results of the experiment performed using the standard procedure (shown in a), results of a significantly longer exposition of the same gel during autoradiography are demonstrated (b) to show products corresponding to activities of other promoters. Analogous experiments, but with E. coli cells cultured at the exponential phase in LB medium (LB exp) and at the stationary phase (st) in various media (LB, MMGlu, MMGly, MMSuc, MMAce) are shown in c. In control experiments, levels of the $r s d(\mathbf{d})$ and $f i m B$ (e) transcripts in E. coli wt cells (WT), and ppGpp ${ }^{0}$ (relA spoT double mutant), $\mathrm{DksA}^{0}$ (dksA::kan mutant) and $\mathrm{ppGpp}^{0}$ $\mathrm{DksA}^{0}$ (relA spoT $d k s A$ triple mutant) derivatives cultured at the stationary phase (d) or the exponential phase (e) in LB medium. Primer extension experiments were performed with Rsd.rev and FimB.rev primers, and the products of the reactions were separated during polyacrylamide gel electrophoresis, with the products of the sequencing reaction (performed using the same primer) run at the same gel (lanes $G, A, T$ and $C$ ) 
Jasiecki and Wegrzyn 2006b), thus, suggesting the source of ostensible discrepancies between the results. Nevertheless, it appears that $\mathrm{pB}$ is the major promoter for $p c n B$ expression under various growth conditions of $E$. coli cultures.

Activity of the $\mathrm{pB}$ promoter in the stationary phase of growth

Although the $\mathrm{pB}$ promoter was active in bacteria cultured in both rich (LB) and minimal (MMGlu) media during the exponential growth (Fig. 2a), we found that its activity is drastically reduced at the stationary phase of growth (Fig. 2c). This impairment of the $\mathrm{pB}$ activity was independent of the growth medium, as similar results were observed in LB and MMGlu, as well as in other minimal media, in which various carbon sources were employed (Fig. 2c).

Since we observed a lack or drastically decreased level of particular signals on gels in samples derived from stationary phase bacterial cultures (Fig. 2), one might argue that this effect could result from a putative general process occurring under specific experimental conditions and causing either impaired transcription or enhanced RNA degradation. However, in control experiments, we were able to detect other transcripts, specific for $r s d$ (Fig. 2d) or fimB (Fig. 2e) genes which were demonstrated previously to occur in starved E. coli cells (Jishage and Ishihama 1999) or to be differentially regulated by ppGpp and DksA (Aberg et al. 2008), respectively, in the same samples which were employed for analyses of $p c n B$ transcription. These experiments served also as internal controls for RNA preparation quality.

ppGpp and DksA inhibit transcription from $\mathrm{pB}$

Under conditions of nutritional starvation, which occur also in bacteria being in the stationary phase of growth, the level of ppGpp, a mediator of the stringent response of bacterial metabolism to starvation conditions, increases significantly (for a recent review, see Potrykus and Cashel 2008). It was demonstrated that ppGpp interacts directly with RNA polymerase. Recent studies indicated that the DksA protein plays an important role in modulation of the ppGpp action on transcription efficiency from various promoters (for reviews, see Szalewska-Palasz et al. 2007b; Potrykus and Cashel 2008). Therefore, we have estimated levels of $\mathrm{pB}$-derived transcripts in wild-type cells as well as in the relA spoT mutant (unable to produce ppGpp, called $\operatorname{ppGpp}^{0}$ ), $d k s A$ mutant (called $\mathrm{DksA}^{0}$ ), and the relA spoT $d k s A$ strain (called $\mathrm{ppGpp}^{0} \mathrm{DksA}^{0}$ ).

Since expression of the ompA gene is maintained at constant levels in relA strains (Durfee et al. 2008), we have estimated abundance of ompA transcripts (Fig. 3a) in the tested samples to normalize results according to this internal control. Increased levels of transcripts derived from $\mathrm{pB}$ were observed in exponentially growing bacteria devoid of ppGpp, DksA or both (Fig. 3b). However, even more dramatic changes in abundance of these transcripts could be observed when RNA samples from stationary phase cells were analyzed. The signal in the sample from the $d k s A$ mutant was significantly higher than that from the wild-type strain, and levels of the studied transcript derived from both $\mathrm{ppGpp}^{0}$ and $\mathrm{ppGpp}^{0} \mathrm{DksA}^{0}$ strains were comparable to those estimated for exponentially growing wild-type cells (Fig. 3c). Therefore, we suggest that a combined action of ppGpp and DksA is responsible for dramatically decreased transcription from the $\mathrm{pB}$ promoter during stationary phase of bacterial culture growth.

Results of the in vivo experiments, suggesting inhibition of $\mathrm{pB}$ activity by ppGpp and DksA, were confirmed in the in vitro transcription reactions, in which production of pB-initiated transcripts in the presence or absence of ppGpp, DksA or both, was tested. DksA weakly inhibited this transcription, while significantly more pronounced impairment of pB activity was caused by ppGpp (Fig. 4). Importantly, a dramatic decrease in the level of pB-derived transcripts was observed when both DksA and ppGpp were present in the reaction mixture (Fig. 4). In control experiments, we have demonstrated that effects of ppGpp and DksA on the activity of the $\lambda p_{\mathrm{R}}$ promoter were very different from those found for $\mathrm{pB}$ (Fig. 4), indicating specificity of the effects on $\mathrm{pB}$ and expected activity of purified reaction compounds.

$\sigma^{70}$ - and $\sigma^{\mathrm{S}}$-dependent transcription of $p c n B$

The $\mathrm{pB}$ promoter sequence, proposed by Binns and Masters (2002), may correspond to the sequence recognized by RNA polymerase holoenzyme containing the $\sigma^{70}$ subunit $\left(\mathrm{E} \sigma^{70}\right)$ (Fig. 1). However, since some E. coli $\sigma$ factors may be responsible for recognizing similar promoter sequences, we tested whether $\mathrm{pB}$ is a $\sigma^{70}$-dependent promoter indeed.

The rpoD800 mutation results in production of the $\sigma^{70}$ subunit whose activity is impaired at elevated temperatures (Liebke et al. 1980; Lowe et al. 1981). We found that abundance of the pB-derived transcripts increased in wild-type bacteria shortly ( $15 \mathrm{~min}$ ) after the transfer of cultures from 37 to $45^{\circ} \mathrm{C}$, while the signals were comparable in the rpoD800 mutant before and after the temperature shift (Fig. 5).

DNA footprinting experiments, performed with $\mathrm{E} \sigma^{70}$ and the template encompassing the $\mathrm{pB}$ promoter region, indicated that the RNA polymerase holoenzyme binds to this DNA fragment, though apparently the promoter was not fully occupied with the protein, which may support previous suggestions (Binns and Masters 2002; Jasiecki and Wegrzyn 2006b) that pB is not a strong promoter (Fig. 6).

The results described above strongly suggested that $\mathrm{pB}$ is a $\mathrm{E} \sigma^{70}$-dependent promoter. However, to verify this 
Fig. 3 Effects of ppGpp and DksA on the ompA gene expression (a) and the $\mathrm{pB}$ promoter activity (b, c). Wild-type (WT) E. coli or $\mathrm{ppGpp}^{0}$ (relA spoT double mutant), $\mathrm{DksA}^{0}$ (dksA::kan mutant) and $\mathrm{ppGpp}^{0}$ $\mathrm{DksA}^{0}$ (relA spoT dksA triple mutant) strains were cultured in the LB medium at $37^{\circ} \mathrm{C}$ to exponential (a and exp in b) or stationary (st in b) phase of growth. Primer extension experiments were performed as described in "Materials and methods", and the products of the reactions were separated during polyacrylamide gel electrophoresis, with the products of the sequencing reaction (performed using the same primer) run at the same gel (lanes $G, A, T$ and $C$ ). a and b show representative autoradiograms (positions of the products of primer extension reactions, corresponding to transcripts originating from $o m p A$ and $\mathrm{pB}$ promoters, are shown). c demonstrates quantification (by densitometric analysis) of the results exemplified in b (mean values from three independent experiments are shown in $\mathbf{c}$ with error bars indicating $\mathrm{SD)}$

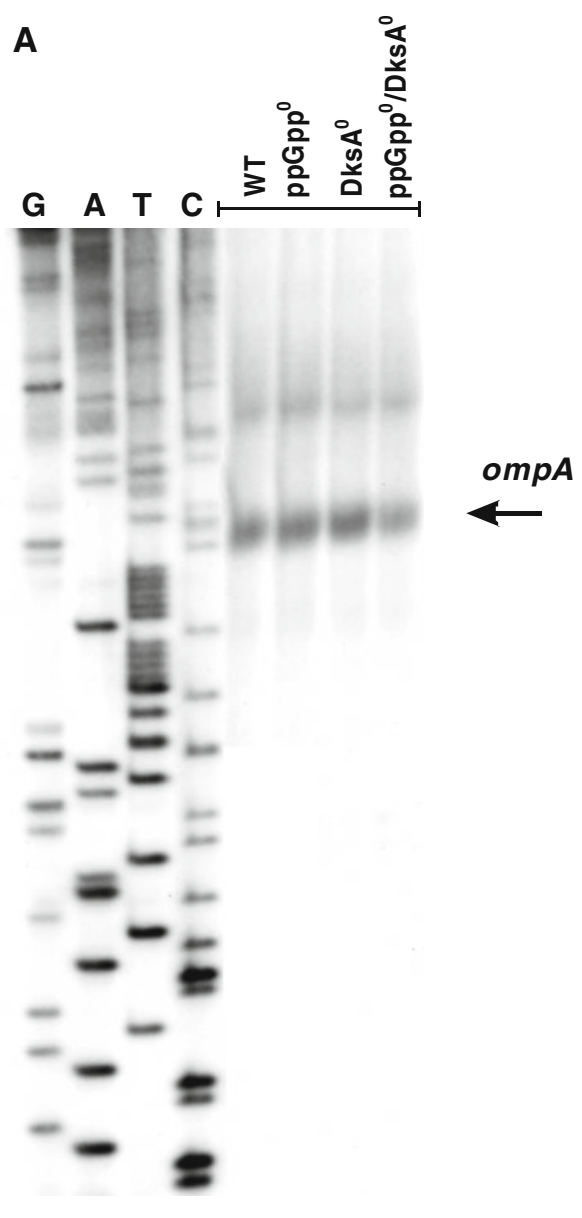

B
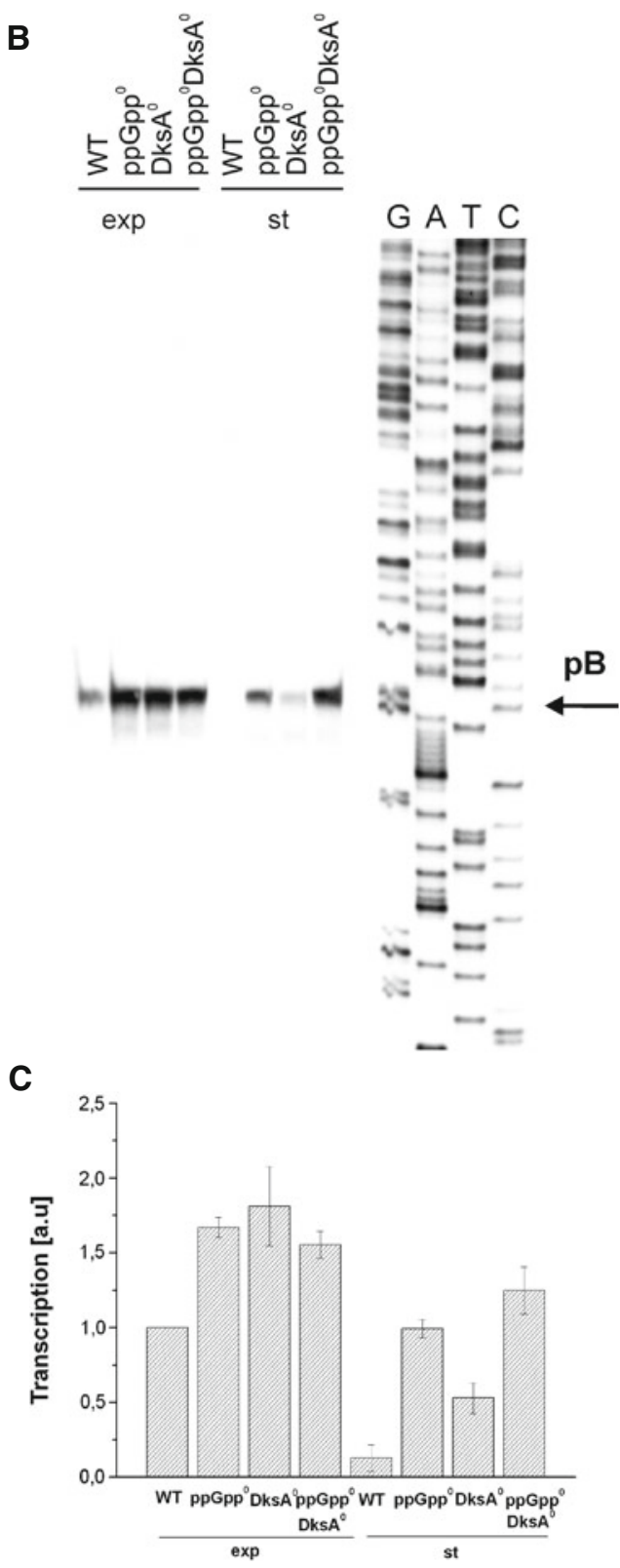

hypothesis, we have performed in vitro transcription reactions with the DNA template containing the $\mathrm{pB}$ promoter sequence and RNA polymerase holoenzymes containing different $\sigma$ subunits, namely: $\sigma^{70}, \sigma^{54}, \sigma^{32}, \sigma^{\mathrm{S}}$, and $\sigma^{\mathrm{E}}$. To identify precisely products of these reactions, the obtained transcripts were subjected to primer extension reactions. As demonstrated in Fig. 7, specific products were obtained when $\mathrm{E} \sigma^{70}$ or $\mathrm{E} \sigma^{\mathrm{S}}$ was used in the in vitro transcription reaction. No products could be detected in experiments with $\mathrm{E} \sigma^{54}, \mathrm{E} \sigma^{32}$, and $\mathrm{E} \sigma^{\mathrm{E}}$ (data not shown). Interestingly, it appears that apart from $\mathrm{pB}$, which is a $\sigma^{70}$-dependent promoter but can also be weakly recognized by $\mathrm{E} \sigma^{\mathrm{S}}$ (Fig. 7), there is another promoter, whose activity is weak in the presence of $\mathrm{E} \sigma^{70}$, but which is active in the presence of $\mathrm{E} \sigma^{\mathrm{S}}$ (Fig. 7). The transcription start site of this promoter, which we named $\mathrm{pS} 1$, corresponds exactly to the localization of the putative promoter of the $p c n B$ gene, proposed previously (Liu and Parkinson 1989) (compare Figs. 1 and 7). That proposal was subsequently suggested to be erroneous (Jasiecki and Wegrzyn 2006b), in the light of the work by Binns and Masters (2002). Nevertheless, our results (Fig. 7) indicated that $\mathrm{pS} 1$ may be a functional promoter, but recognized considerably more effectively by $\mathrm{E} \sigma^{\mathrm{S}}$ than by $\mathrm{E} \sigma^{70}$.

Two $\sigma^{\mathrm{S}}$-dependent promoters are located in the region upstream of the $p c n B$ gene

By using the in vitro transcription system allowing to obtain longer transcripts, we found that in the region of the $p c n B$ gene there are two promoters (rather than only one) 


\section{DksA (nM)}

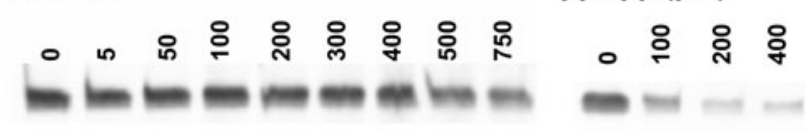

DksA $(\mathrm{nM})+$ ppGpp $(200 \mu \mathrm{M})$

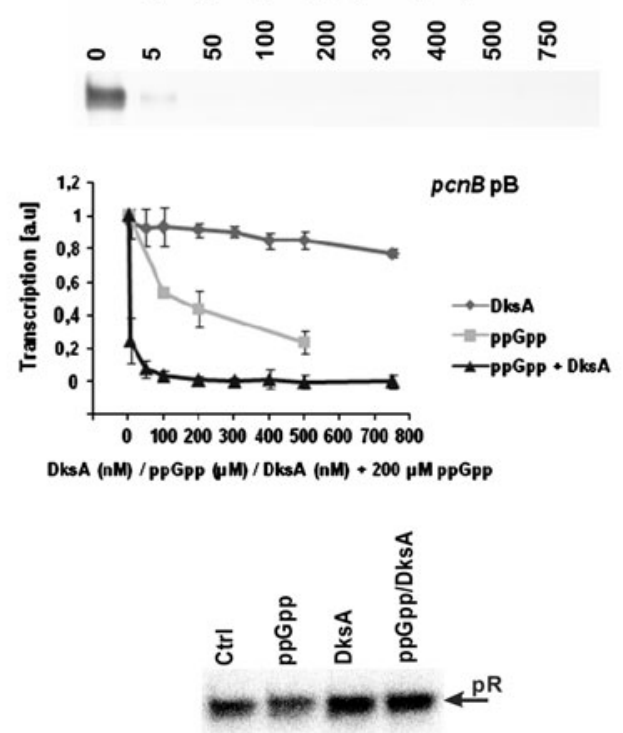

Fig. 4 Effects of DksA and ppGpp on in vitro transcription from the $\mathrm{pB}$ promoter. Representative results are shown on autoradiograms, and the summary of the results (mean values from three experiments with error bars indicating SD) is shown at the diagram (the presence of following factors in the reaction mixture is shown: diamonds DksA, squares ppGpp, triangles DksA and ppGpp). In control experiments, analogous reactions were performed with the $\lambda p_{\mathrm{R}}$ promoter (the bottom panel), with either no additional factors (Ctrl), ppGpp (200 $\mu \mathrm{M})$, DksA (400 nM) or ppGpp and DksA (200 $\mu \mathrm{M}$ and $400 \mathrm{nM}$, respectively)

whose activities are evident in the presence of $\mathrm{E} \sigma^{\mathrm{S}}$ (Fig. 8a). Apart from the $\sigma^{70}$-dependent transcription signal from $\mathrm{pB}$, and the two $\sigma^{\mathrm{S}}$-dependent signals (pS1 and $\mathrm{pS} 2$ ), no other transcription initiation signals could be detected in this region with the use of all other tested $\sigma$ factors (Fig. 8a).

The region of transcription initiation from the second $\sigma^{\mathrm{S}}$-dependent promoter for $p c n B$, called $\mathrm{pS} 2$, was determined in primer extension experiments, in which RNAs obtained in in vitro transcription experiments were employed as templates (Fig. 8b). Note that there are perhaps at least two alternative start sites from $\mathrm{pS} 2$, located in the region between positions -263 and -265 relative to the translation start codon ATT.

The regions of the $\mathrm{pS} 1$ and $\mathrm{pS} 2$ promoters are shown in Fig. 8 c. While putative -10 and -35 boxes can be easily predicted for $\mathrm{pS} 1$, in the case of $\mathrm{pS} 2$, it is possible to predict only -10 element (TAAACT), whereas there is no obvious -35 box. On the other hand, both $\mathrm{pS} 1$ and $\mathrm{pS} 2$ sequences bear the $\mathrm{C}$ residue in the neighborhood of the -10 element.

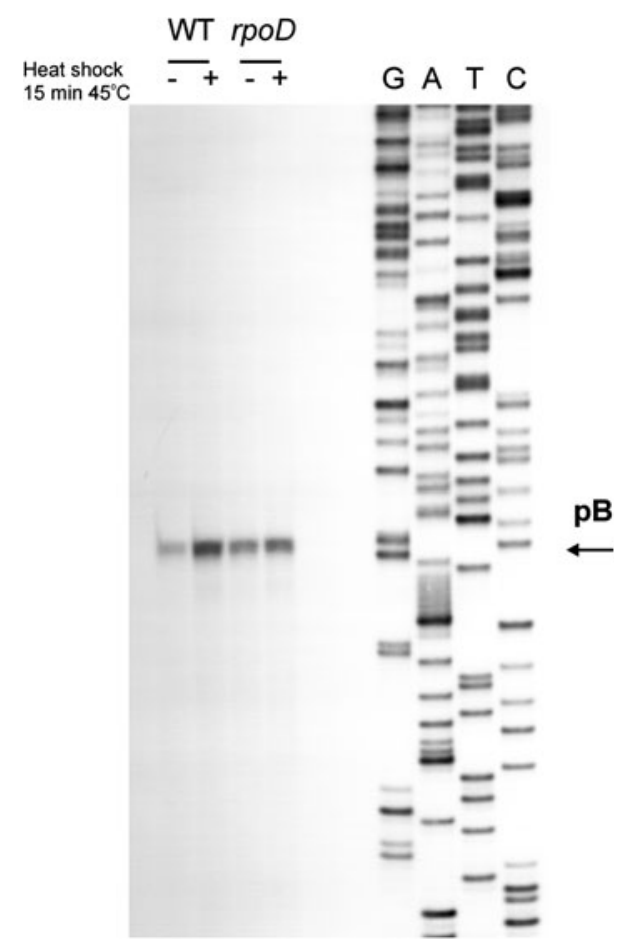

Fig. 5 Effects of heat shock on levels of pB-derived transcripts in E. coli wild-type (WT) bacteria and the rpoD800 (rpoD) mutant. Bacteria were cultured to $A_{575}$ of 0.4 (exponential phase) and then one half of the culture was transferred to $45^{\circ} \mathrm{C}(+)$ while the second half remained at $37^{\circ} \mathrm{C}(-)$. Following further cultivation for $15 \mathrm{~min}$, RNA was isolated and primer extension experiments were performed as described in "Materials and methods". The position of the products of primer extension reactions, corresponding to transcripts originating from the $\mathrm{pB}$ promoter, is shown

Such a residue is known to be crucial for selective recognition of promoters dependent on $\mathrm{E}^{\mathrm{S}}$ (Lacour et al. 2003).

Activity of the $\sigma^{\mathrm{S}}$-dependent promoters

of the $p c n B$ gene in vivo

We asked whether the $\sigma^{\mathrm{S}}$-dependent promoters detected in in vitro experiments are active in vivo. To address this question, primer extension experiments were performed. Wild-type bacteria as well $r p o S$ and $\mathrm{ppGpp}^{0}$ mutants were cultured in LB broth, and samples were withdrawn at the exponential and stationary phases of growth. Following RNA isolation, the primer extension experiments revealed no detectable signal from the $\mathrm{pS} 1$ promoter in exponentially growing cells, as expected. Surprisingly, also no such a signal could be observed in samples from stationary phase wild-type bacteria (Fig. 9). However, a signal corresponding to the pS1-initiated transcription was evident in the ppGpp $^{0}$ mutant. This transcription was $\sigma^{\mathrm{S}}$-dependent as it was totally impaired in the rpoS mutant, irrespective of the presence or absence of ppGpp (Fig. 9). 


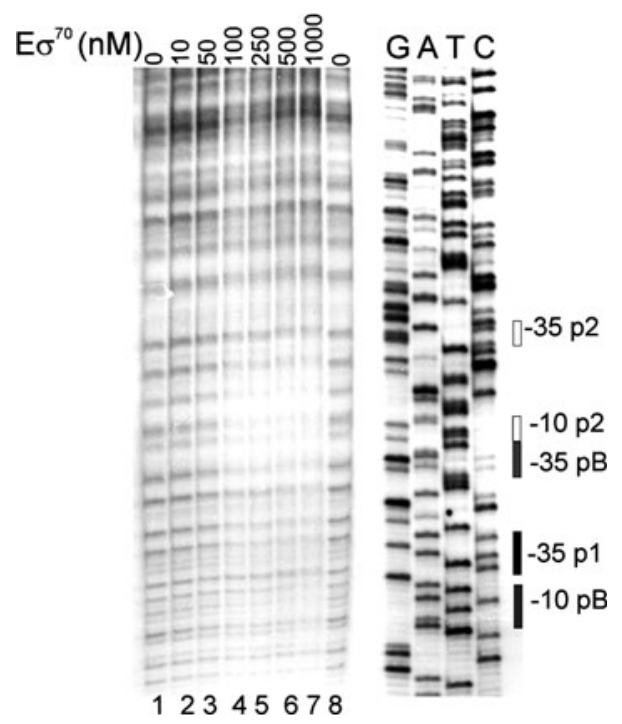

Fig. 6 Interaction of $\mathrm{E} \sigma^{70}$ with the promotor region of the $p c n B$ gene as assessed by DNase I footprinting. A ${ }^{32} \mathrm{P}$-labeled $0.3 \mathrm{~kb}$ DNA fragment was incubated with $0 \mathrm{nM}$ (negative control, lanes 1 and 8 ), $10 \mathrm{nM}$ (lane 2), $50 \mathrm{nM}$ (lane 3), $100 \mathrm{nM}$ (lane 4), $250 \mathrm{nM}$ (lane 5), $500 \mathrm{nM}$ (lane 6) or 1,000 $\mathrm{nM}$ (lane 7) $\sigma^{70}$. The footprinting experiments were performed as described in "Materials and methods". The -10 and -35 sequences of $\mathrm{p} 1, \mathrm{pB}$ and $\mathrm{p} 2$ are indicated

Results analogous to those described above were obtained when the pS2 promoter was tested. Its activity could be detected only in the stationary phase of bacterial growth in the absence of ppGpp and in the presence of $\sigma^{\mathrm{S}}$ activity (Fig. 10).

The $\mathrm{pS} 1$ and $\mathrm{pS} 2$ promoters are negatively regulated by ppGpp in vivo

Since pS1 and pS2 activities appeared to be negatively regulated by ppGpp, we have tested their responses to lack of either one or two major effectors of the stringent response, ppGpp and DksA, in bacteria from stationary phase of growth. Both promoters were inactive in the presence of ppGpp, irrespective of the activity of DksA (Fig. 11). These results suggest that ppGpp is the main negative regulator of $\mathrm{pS} 1$ and $\mathrm{pS} 2$ in vivo.

The $\mathrm{pS} 1$ and $\mathrm{pS} 2$ promoters are negatively regulated by ppGpp and DksA in vitro

To test whether the ppGpp-mediated negative regulation of activities of $\mathrm{pS} 1$ and $\mathrm{pS} 2$ in vivo is direct or indirect, we have performed in vitro transcription experiments. Again, both promoters responded in the same way to the presence of ppGpp and/or DksA in the reaction mixture. The DksA protein alone had little, if any, effect on transcription from

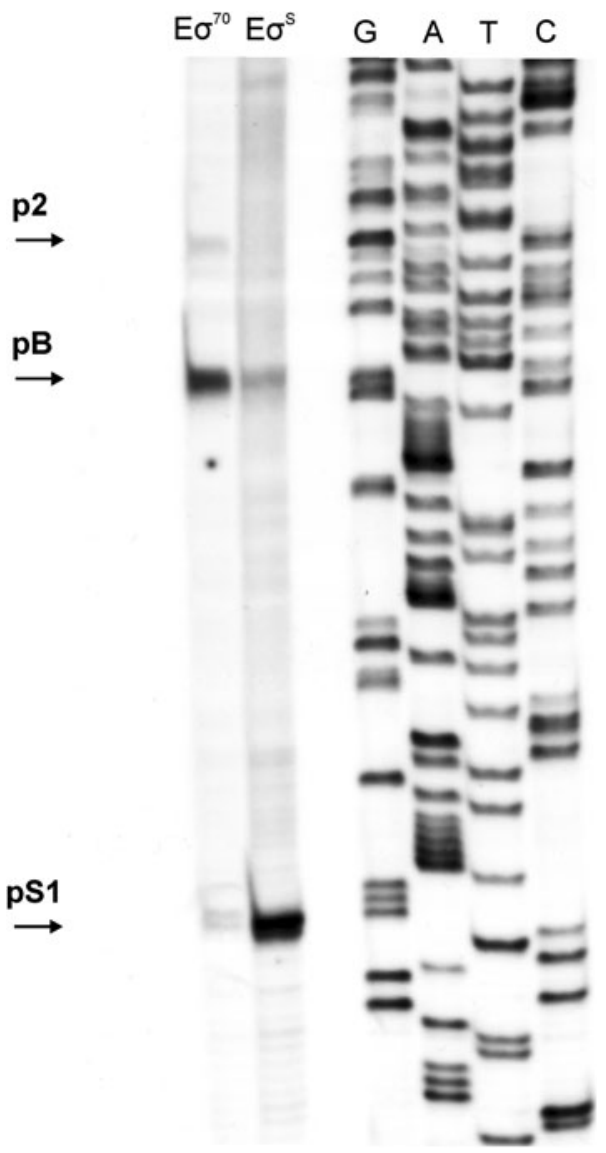

Fig. 7 Effects of the presence of different $\left(\sigma^{70}\right.$ or $\left.\sigma^{\mathrm{S}}\right)$ sigma factors on in vitro transcription from $p c n B$ promoters. Primer extension experiments were performed with primer pcnTR2 (as described in Fig. 2) using templates obtained in the in vitro transcription reactions, and either $\mathrm{E} \sigma^{70}$ or $\mathrm{E} \sigma^{\mathrm{S}}$. Positions corresponding to transcripts derived from $\mathrm{pS} 1, \mathrm{pB}$ and $\mathrm{p} 2$ promoters are marked by arrows

both tested promoters (Fig. 12a-d). A marked and concentration-dependent impairment of $\mathrm{pS} 1$ and $\mathrm{pS} 2$ activities could be detected in the presence of ppGpp. These results indicate that the effects of this nucleotide on transcription from these two promoters are direct. Although DksA alone was not able to inhibit activities of $\mathrm{pS} 1$ and $\mathrm{pS} 2$ significantly, this protein enhanced the inhibitory effects of ppGpp, when present together with this nucleotide in the reaction mixture (Fig. 12a-d).

To test whether the effects of ppGpp and DksA are specific to $\mathrm{pS} 1$ and $\mathrm{pS} 2$, we have performed control experiments with a template containing a promoter demonstrated previously to be unaffected by these factors. The $\lambda p_{\mathrm{L}}$ promoter appeared to be a good candidate for such a control. Indeed, we found no significant effects of ppGpp and/or DksA on pL-initiated transcription (Fig. 12e-g). Therefore, we conclude that there is a specific negative regulation of pS1 and pS2 by ppGpp and DksA. 


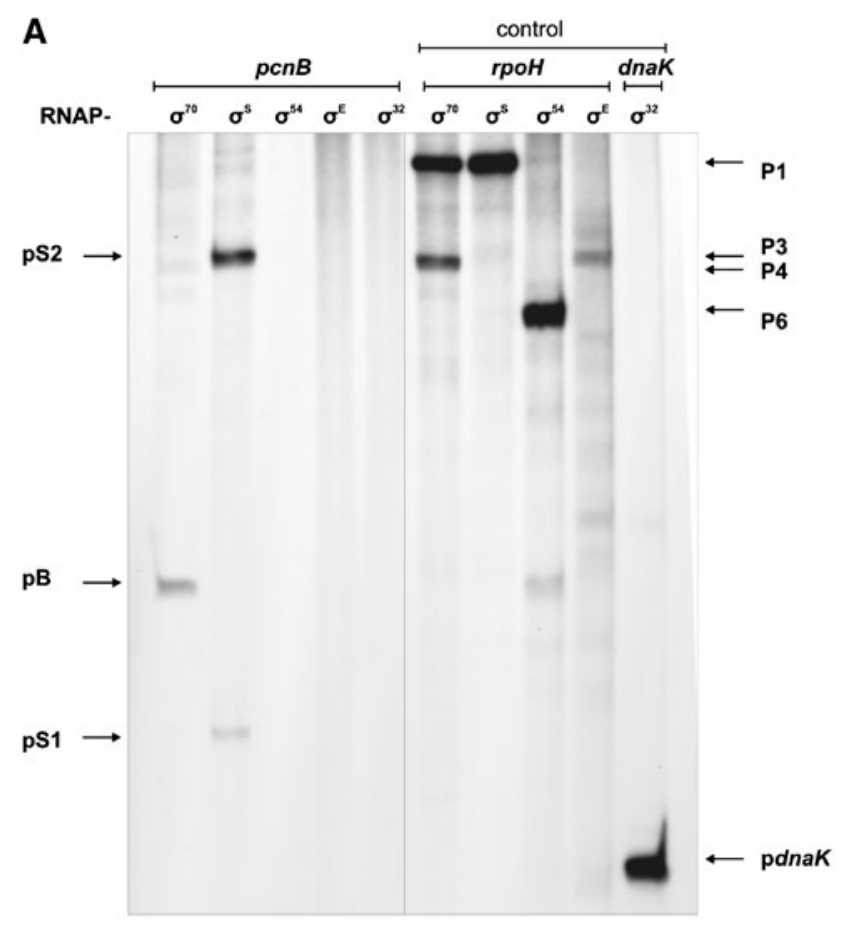

Fig. 8 In vitro transcription from the region of the $p c n B$ gene (a) and mapping of the $\mathrm{pS} 2$ transcription start sites (b). In experiments shown in a, E. coli RNA polymerase holoenzymes bearing different $\sigma$ factors (marked above particular lanes) were used in the reactions performed as described in "Materials and methods". Positions of transcripts derived from $\mathrm{pB}, \mathrm{pS} 1$ and $\mathrm{pS} 2$ promoters are indicated. In the control experiment, activities of all holoenzymes were demonstrated by employing DNA templates containing promoters specific for vari-

\section{Discussion}

Since polyadenylation of bacterial RNA plays a role in the regulation of expression of as many as $90 \%$ of genes (for a review, see Regnier and Hajnsdorf 2009), it is clear that determination of mechanisms leading to different efficiency of adding poly(A) tails at the $3^{\prime}$ ends of transcripts is required to understand this specific control process. On the other hand, regulation of RNA polyadenylation efficiency in $E$. coli is relatively poorly understood. It was demonstrated that both production of PAP I and polyadenylation reaction are inversely correlated to bacterial growth rate (Jasiecki and Wegrzyn 2003). However, only basic information on expression of the $p c n B$ gene, coding for PAP I, was available to date. It appeared that there are at least three promoters located upstream of the pcnB coding sequence (Jasiecki and Wegrzyn 2006b) and that synthesis of PAP I may also be regulated at the level of translation
B
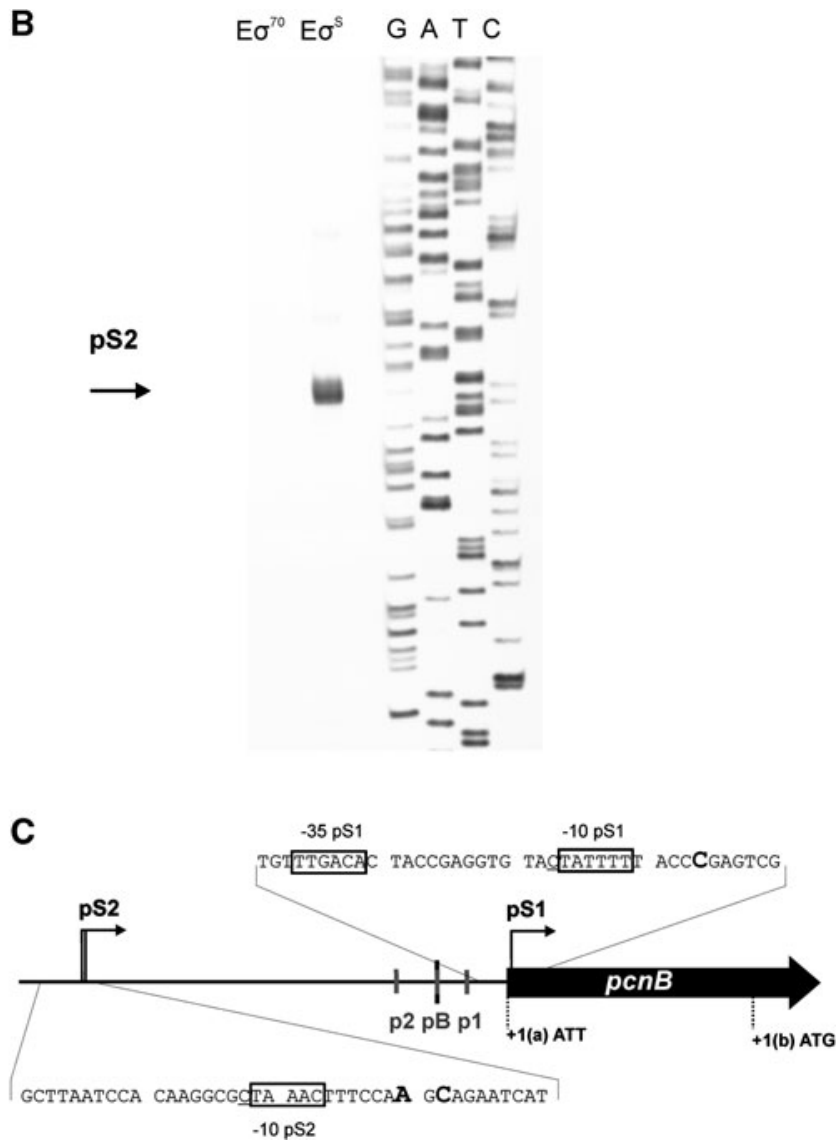

ous $\sigma$ factors (templates with the $r p o H$ gene promoter region and the dnaK gene promoter region, described by Janaszak et al. 2007, were used); positions of bands corresponding for transcripts originating from particular promoters are indicated. In experiments shown in $\mathbf{b}$, primer extension experiments with primer PS2.rev were performed using the products of in vitro transcription reactions as templates. In $\mathbf{c}$, proposed localization of $\mathrm{pS} 1$ and $\mathrm{pS} 2$ promoters in the region upstream of the coding sequence of the $p c n B$ gene is shown

initiation (Binns and Masters 2002). Moreover, PAP I was found to be a substrate for phosphorylation, and this modification may influence the enzyme activity (Jasiecki and Wegrzyn 2006a).

Results demonstrated in this report indicated that among all $p c n B$ promoters, $\mathrm{pB}$ is the major one in bacteria growing in both rich and minimal media. We also conclude that $\mathrm{p} 1$ and $\mathrm{p} 2$ may have only minor roles in the control of $p c n B$ expression, though they are still active promoters (compare Figs. 2a and 7). The differences in relative activities of $\mathrm{pB}$, $\mathrm{p} 1$ and $\mathrm{p} 2$ reported in three papers, this one and published previously (Binns and Masters 2002; Jasiecki and Wegrzyn 2006b), may be due to various growth conditions used in different studies (rich vs. minimal media) and various conditions ("stringent" vs. "relaxed") of primer extension reactions. One should also note that activities of the fusions of $\mathrm{pB}, \mathrm{p} 1$ and $\mathrm{p} 2$ with lacZ, reported previously (Jasiecki and Wegrzyn 2006b), reflected collective activities of 


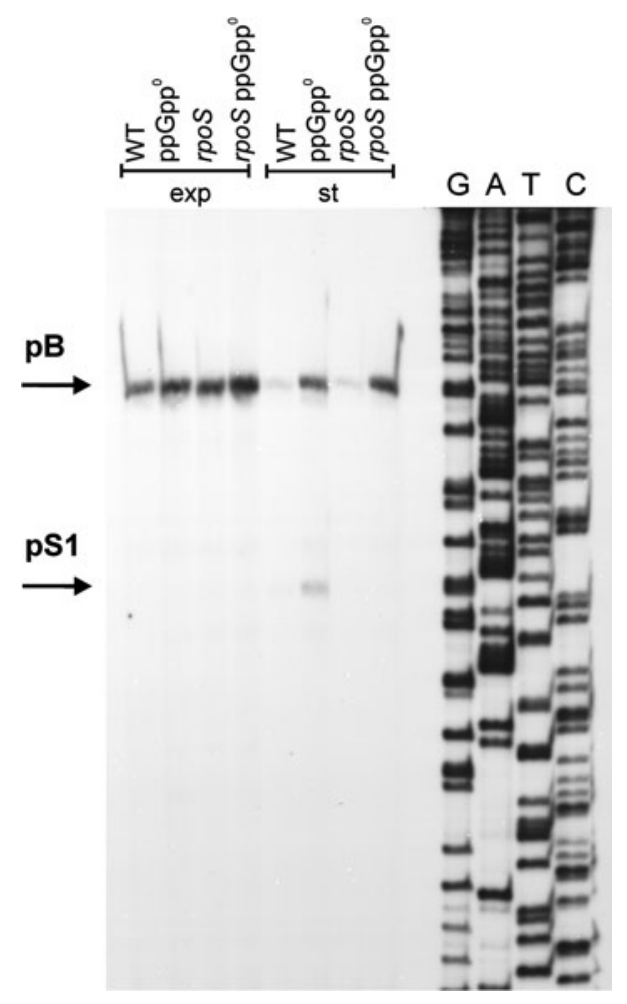

Fig. 9 Activity of the pS1 promoter in vivo and its dependence on the rpoS gene function. Wild-type (WT) E. coli or $\mathrm{ppGpp}^{0}$ (relA spoT double mutant), rpoS and $\mathrm{ppGpp}^{0}$ rpos (relA spoT rpoS triple mutant) strains were cultured in the LB medium at $37^{\circ} \mathrm{C}$ to exponential (exp) or stationary (st) phase of growth. Primer extension experiments were performed with primer PS1.rev as described in "Materials and methods", and the products of the reactions were separated during polyacrylamide gel electrophoresis, with the products of the sequencing reaction (performed using the same primer) run at the same gel (lanes $G, A$, $T$ and $C$ )

different promoters, rather than those of individual promoters, due to close proximity of their sequences. Moreover, these fusions contained only short fragments of sequences located beyond -10 and -35 regions of tested promoters; thus, they might lack important regulatory sequences. This may explain why only weak activity of $\mathrm{pB}$ could be detected when a fusion containing only -10 and -35 boxes of this promoter was tested in bacteria grown in minimal media (Jasiecki and Wegrzyn 2006b).

Interestingly, transcription of the $p c n B$ gene was found to be drastically inhibited at the stationary phase of growth. The stringent control alarmone, ppGpp, and the DksA protein are responsible for this inhibition as mutations in genes that lead to the absence of ppGpp and DksA caused restoration of transcription from $\mathrm{pB}$ in cells from the stationary phase to the level estimated in exponentially growing wildtype bacteria. Moreover, $\mathrm{pB}$ activity was also impaired by ppGpp and DksA in a purified in vitro transcription system. This is interesting in the light of previous findings that both $p c n B$ transcription and PAP I levels are inversely

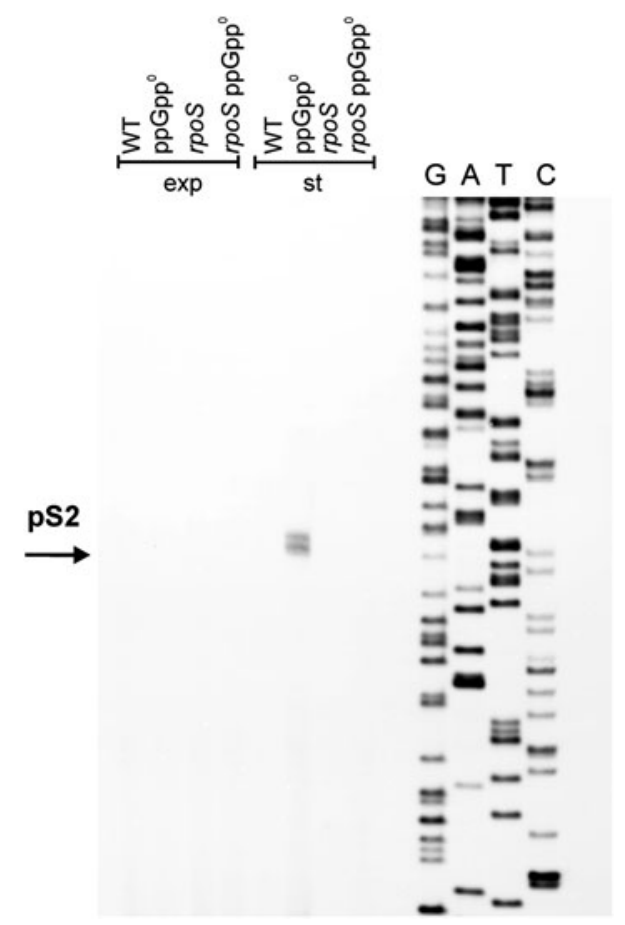

Fig. 10 Activity of the pS2 promoter in vivo and its dependence on the $r p o S$ gene function. Wild-type (WT) E. coli or $\mathrm{ppGpp}^{0}$ (relA spoT double mutant), rpoS and $\mathrm{ppGpp}^{0}$ rpos (relA spoT rpoS triple mutant) strains were cultured in the LB medium at $37^{\circ} \mathrm{C}$ to exponential (exp) or stationary (st) phase of growth. Primer extension experiments were performed with primer PS2.rev as described in "Materials and methods", and the products of the reactions were separated during polyacrylamide gel electrophoresis, with the products of the sequencing reaction (performed using the same primer) run at the same gel (lanes $G, A$, $T$ and $C$ )

proportional to bacterial growth rate (Jasiecki and Wegrzyn 2003). Since ppGpp levels increase moderately in slowly growing E. coli cells (see Potrykus and Cashel 2008, for a review), one might speculate that effects opposite to those described in this report could occur at the stationary phase of growth. However, it appears that physiological processes may be controlled differentially in slowly growing and nongrowing bacteria. We suppose that physiological significance of such a regulation may reflect the control of energy resources in bacterial cells. In slowly growing cells, enhanced expression of certain genes might be required, and under poor nutritional conditions, nucleotides necessary for transcription of these genes could be obtained from rapidly degraded transcripts. Thus, an increased level of $p c n B$ transcription (and expression), and resultant more efficient RNA polyadenylation and its more rapid degradation, might provide sufficient pool of nucleotides. However, when cell growth is totally inhibited, like at the stationary phase, production of an excess of PAP I, and subsequent intensive RNA polyadenylation, would be a waste of energy. Moreover, PAP I was proposed to be toxic for cells when occurring at significantly elevated levels 
Fig. 11 Effects of ppGpp and DksA on the pS1 (a) and pS2 (b) promoter activity. Wild-type (WT) E. coli or $\mathrm{ppGpp}^{0}$ (relA spoT double mutant), $\mathrm{DksA}^{0}$ (dksA::kan mutant) and ppGpp ${ }^{0}$ $\mathrm{DksA}^{0}$ (relA spoT dksA triple mutant) strains were cultured in the $\mathrm{LB}$ medium at $37^{\circ} \mathrm{C}$ to exponential (exp) or stationary (st) phase of growth. Primer extension experiments were performed as described in "Materials and methods", with the use of PS1.rev primer (left panel) and PS2.rev primer (right panel), and the products of the reactions were separated during polyacrylamide gel electrophoresis, with the products of the sequencing reaction (performed using the same primers) run at the same gel (lanes $G, A, T$ and $C$ ). Positions corresponding to $\mathrm{pB}, \mathrm{pS} 1$ and $\mathrm{pS} 2$ transcription start sites are shown

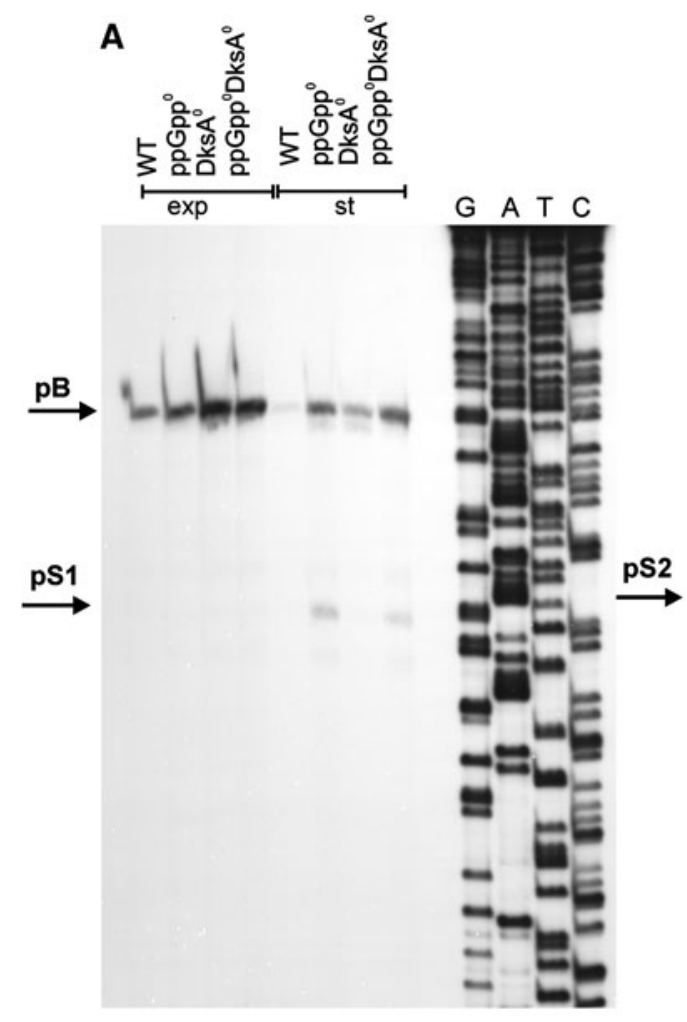

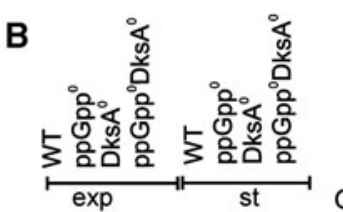

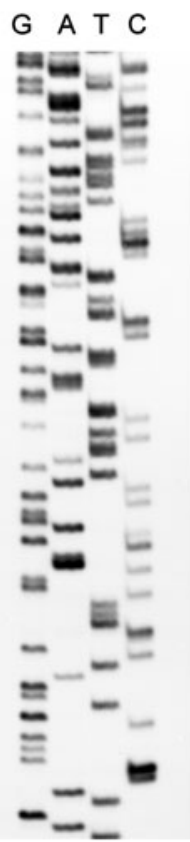

(Binns and Masters 2002); thus, an impaired transcription of $p c n B$ might be a mechanism, which together with a specific regulation of translation from a non-canonical start codon (Binns and Masters 2002) could protect the cell from PAP I toxicity.

The localization of the functional $p c n B$ gene promoter was controversial for several years. Early description of such a promoter, on the basis of nucleotide sequence analysis (Liu and Parkinson 1989), was subsequently criticized as a erroneous, due to demonstration that $p c n B$ translation starts from the AUU codon located upstream of the promoter mentioned above, and identification of another functional promoter (Binns and Masters 2002). Perhaps surprisingly, we have found that the promoter described by Liu and Parkinson (1989), although located downstream of the translation start codon AUU, is also active in vitro, but requires $\mathrm{E} \sigma^{\mathrm{S}}$ for maximal activity (contrary to $\mathrm{pB}$, which is $\mathrm{E} \sigma^{70}$-dependent). This promoter functions also in vivo, but only under specific conditions (inhibition of bacterial culture growth in the absence of ppGpp). As suggested by Liu and Parkinson (1989), there are putative Shine-Dalgarno and AUG sequences that could potentially promote translation of the shorter mRNA produced on the $p c n B$ gene template. It is intriguing that there is a common picture described in the literature, showing that after electrophoretic separation of E. coli proteins and Western blotting, two protein bands react strongly with anti-PAP I antibodies (Jasiecki and Wegrzyn 2003; Mohanty et al. 2004;
Mohanty and Kushner 2006). Comparison of migrations of these two proteins during SDS-PAGE indicates that it is possible that there are two variants of PAP I, one whose translation starts from the AUU codon and the second, initiated at the AUG codon proposed by Liu and Parkinson (1989) (compare Fig. 1). The question whether such a putative N-terminally truncated PAP I is really produced in cells and might function in RNA polyadenylation remains to be answered, especially because one might argue that this is unlikely as pS1 requires specific conditions for its activity.

Although it is reasonable to assume that expression of the $p c n B$ gene must be precisely regulated to avoid PAP I overproduction, one should ask about a physiological role for $\sigma^{\mathrm{S}}$-dependent expression of $p c n B$. We speculate that there might be specific environmental conditions, under which the cells would benefit from enhanced synthesis of PAP I, resulting in liberation of nucleotides from rapidly degraded transcripts, even when cell's growth is halted. This might facilitate expression of specific genes required for bacterial survival, but if so, transcription of the $p c n B$ gene from $\sigma^{\mathrm{S}}$-dependent promoter(s) would be required. However, as demonstrated in this report, $\mathrm{pS} 1$ and $\mathrm{pS} 2$ promoters are active only in the absence of ppGpp. In fact, conditions that inhibit cell growth but do not provoke production of ppGpp can occur, indeed, and may be exemplified by sub-lethal concentrations of toxins or antibiotics. In this light, it is worth reminding that treatment of wild-type E. coli cells with chloramphenicol induces the relaxed 
A
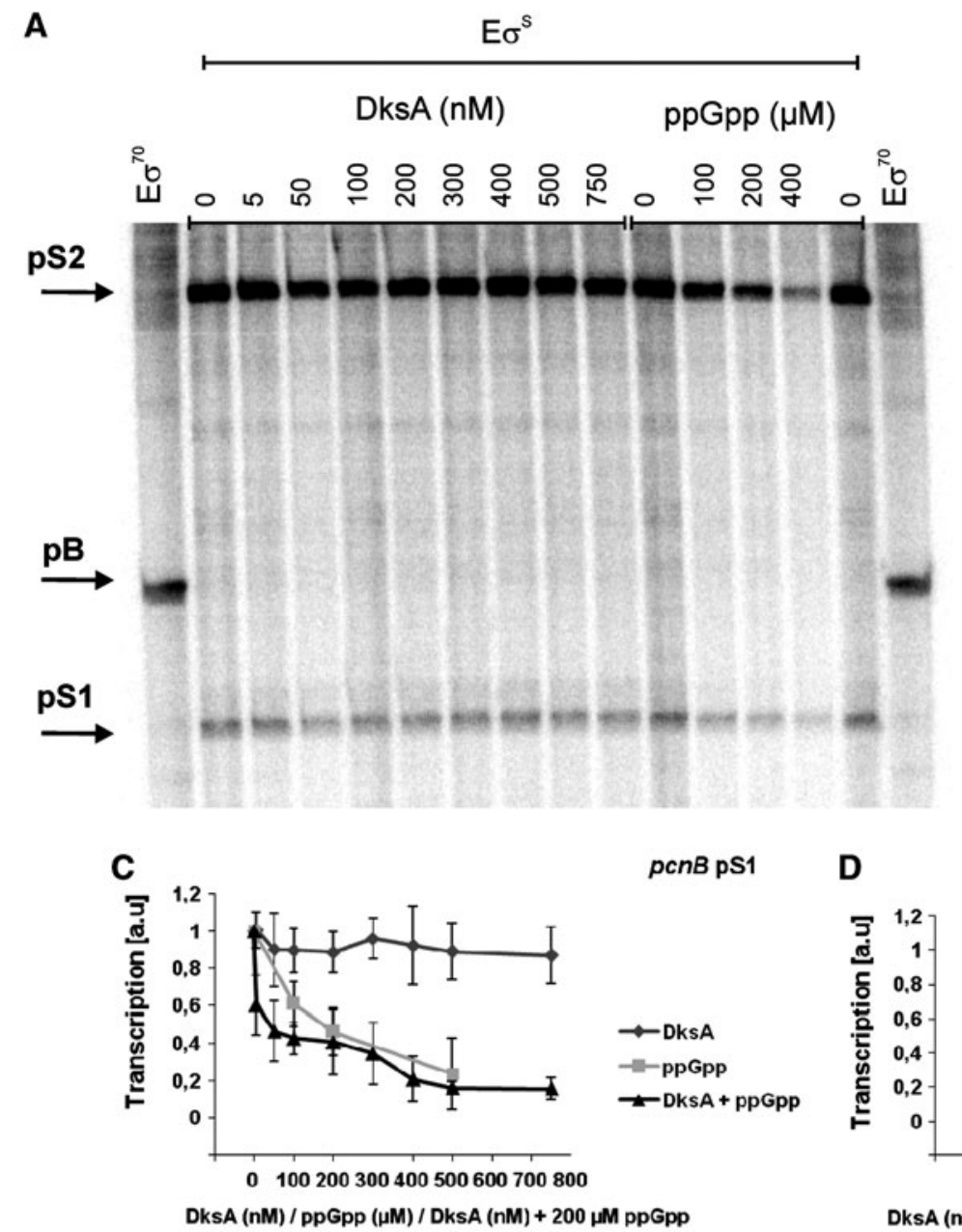

E

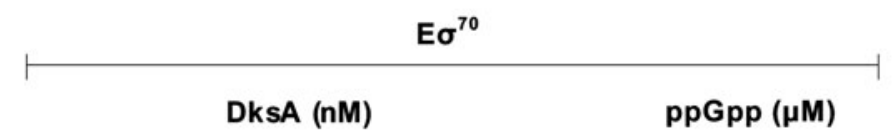

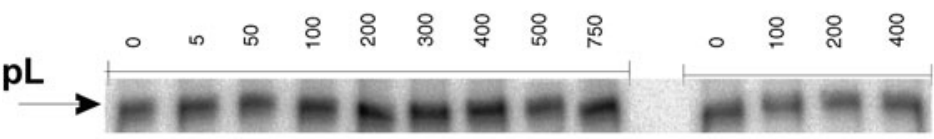

B
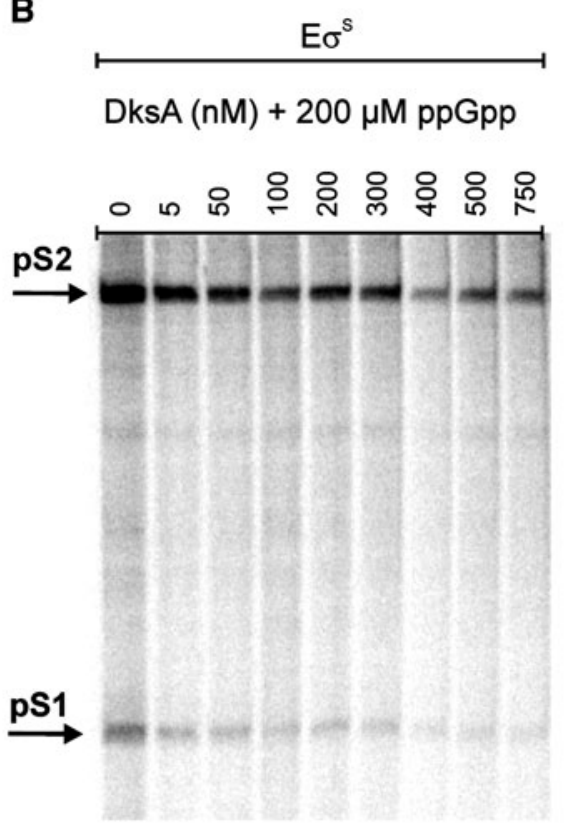

D

pcnB pS2

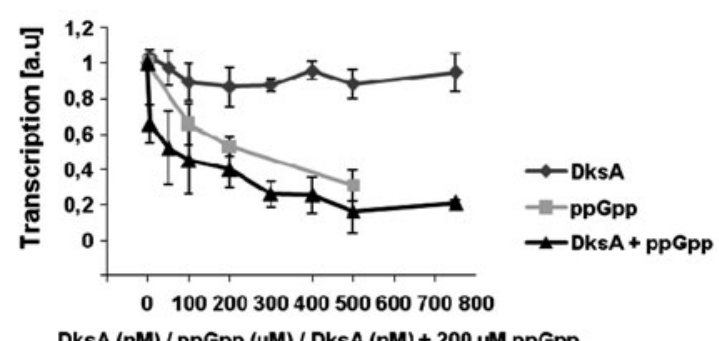

DksA (nM) / ppGpp ( $(\mu \mathrm{M}) /$ DksA (nM) $+200 \mu \mathrm{M}$ ppGpp

$\mathbf{F}$

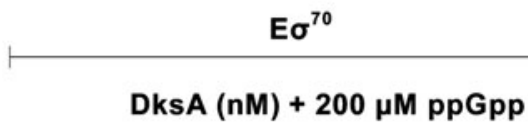

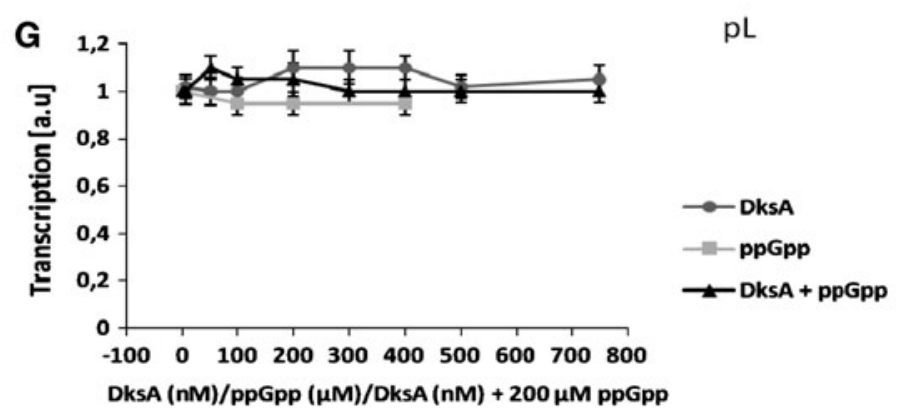

Fig. 12 Effects of DksA and ppGpp on in vitro transcription from the $\mathrm{pS} 1, \mathrm{pS} 2(\mathbf{a}-\mathbf{d})$ and $\lambda p_{\mathrm{L}}(\mathbf{e}-\mathbf{g})$ promoters. Representative results are shown on autoradiograms (a, b, e and $\mathbf{f})$. The presence and concentrations of particular factors in the reaction mixtures are indicated and positions of bands corresponding to certain transcripts are shown.

Summaries of the results (mean values from three experiments with error bars indicating SD) are shown at the diagrams (c, $\mathbf{d}$ and $\mathbf{g})$. The presence of following factors in the reaction mixtures is shown: DksA (diamonds), ppGpp (squares), DksA and ppGpp (triangles) 
response (Baracchini and Bremer 1988), which is defined as a lack of ppGpp production under conditions of protein synthesis inhibition.

Results presented in this report may also shed some light on the mechanism(s) of the transcription regulation under conditions of the stringent control. In the generally accepted models of ppGpp/DksA-mediated regulation of transcription, $\sigma^{70}$-dependent promoters are either inhibited (if they form unstable open complexes) or stimulated (if they form stable open complexes), and transcription from promoters requiring one of alternative $\sigma$ factors can be enhanced according to the passive model, due to releasing RNA polymerase core from $\sigma^{70}$-dependent promoters and facilitating the use of other $\sigma$ factors (for a review, see Srivatsan and Wang 2008). In fact, there are examples of $\sigma^{\mathrm{N}}$ and $\sigma^{\mathrm{E}}$-dependent promoters stimulated under condition of the stringent response in vivo (see, e.g., Bernardo et al. 2006; Costanzo and Ades 2006; Szalewska-Palasz et al. 2007a; Costanzo et al. 2008). Stimulation of $\sigma^{\mathrm{N}}$-dependent promoters by ppGpp/DksA observed in vivo could not be detected in in vitro transcription systems with only one type of the RNA polymerase holoenzyme, $\mathrm{E} \sigma^{\mathrm{N}}$; however, the in vitro competition experiments could support the passive model for transcription regulation by ppGpp and DksA (Laurie et al. 2003; Szalewska-Palasz et al. 2007a).

There are also many examples of positive regulation of transcription from $\sigma^{\mathrm{S}}$-dependent promoters under conditions of the stringent response and/or stationary phase of growth. Efficient expression of genes coding for integration host factor (Aviv et al. 1994), transketolase A (Harinarayanan et al. 2008), OpgG and OpgH (Costa et al. 2009), cyclopropane fatty acid synthase (Eichel et al. 1999), and glutaredoxin 2 (Potamitou et al. 2002) requires both ppGpp and $\mathrm{E} \sigma^{\mathrm{S}}$ in vivo. In fact, expression of the $r p o S$ gene (which is under control of a $\sigma^{70}$-dependent promoter), coding for $\sigma^{\mathrm{S}}$, is stimulated by ppGpp and DksA (Gentry et al. 1993; Lange et al. 1995; Brown et al. 2002; Bougdour and Gottesman 2007). Thus, one might assume that most of the above-mentioned effects are indirect, and result from an increase in the level of this alternative $\sigma$ factor. However, among the promoters requiring ppGpp and $\mathrm{E} \sigma^{\mathrm{S}}$, there are some which are apparently regulated by ppGpp independently from $\mathrm{E} \sigma^{\mathrm{S}}$. Moreover, it was suggested that $\sigma^{\mathrm{S}}$-dependent promoters may require ppGpp for induction even in the presence of high levels of this $\sigma$ factor (Kvint et al. 2000). Therefore, one might propose that apart from the passive model of the transcription stimulation by $\mathrm{ppGpp} /$ DksA under stress conditions, the active model may also operate through direct activation of promoters dependent on alternative $\sigma$ factors (or, more precisely, at least on $\sigma^{\mathrm{S}}$ ) by these effectors of the stringent response. The weak point of such a hypothesis would be a fact that only activation of transcription of $\sigma^{\mathrm{S}}$-dependent promoters by ppGpp/DksA was reported to date. Clearly, a lack of the negative regulation would not be expected in the active model.

To our knowledge, the results presented in this report demonstrate for the first time an experimental evidence for direct inhibition of transcription from $\sigma^{\mathrm{S}}$-dependent promoters by ppGpp/DksA. Therefore, they support the proposal that apart from the passive model of ppGpp/DksA-mediated regulation of transcription initiated by RNA polymerase bearing alternative $\sigma$ factors, the active model may also be operating, at least in the case of $\mathrm{E} \sigma^{\mathrm{S}}$.

In summary, results reported in this article indicate that regulation of transcription of the $p c n B$ gene in $E$. coli is a complex process, controlled by various factors, including different $\sigma$ subunits of RNA polymerase $\left(\sigma^{70}\right.$ and $\left.\sigma^{\mathrm{S}}\right)$ and the stringent response factors (ppGpp and DksA). It appears that this complex regulation of transcription, together with the control of the pcnB expression at the translation initiation stage, described previously (Binns and Masters 2002), ensures production of PAP I in precisely desired amounts, depending on bacterial growth conditions. Moreover, we demonstrated for the first time that activities of $\sigma^{\mathrm{S}}$-dependent promoters may be inhibited by ppGpp and DksA. This discovery supports the hypothesis that regulation of transcription from promoters requiring alternative $\sigma$ factors by these effectors of the stringent response might occur according to both passive and active models. Such a regulation may have a physiological importance for survival of bacteria under specific environmental conditions.

Acknowledgments We thank Katarzyna Brzozowska for her assistance at the early stages of this project. The authors are grateful to Dr. A. Janaszak for providing the $\sigma^{\mathrm{S}}$ and $\sigma^{54}$ proteins, and to E. Stec for providing the $\sigma^{\mathrm{E}}$ protein. We thank Dr. Bernd Bukau for providing the E. coli strain BB2060 (pDMI,1, pUHE211-1) for $\sigma^{32}$ overproduction. This work was supported by the Ministry of Science and Higher Education (Poland) (project grants no. NN301 192439 and NN301 161635, to AW and AS-P, respectively).

Open Access This article is distributed under the terms of the Creative Commons Attribution Noncommercial License which permits any noncommercial use, distribution, and reproduction in any medium, provided the original author(s) and source are credited.

\section{References}

Aberg A, Shingler V, Balsalobre C (2008) Regulation of the fimB promoter: a case of differential regulation by ppGpp and DksA in vivo. Mol Microbiol 67:1223-1241

Artsimovitch I et al (2004) Structural basis for transcription regulation by alarmone ppGpp. Cell 117:299-310

August JT, Ortiz PJ, Hurwitz J (1962) Ribonucleic acid-dependent ribonucleotide incorporation. I. Purification and properties of the enzyme. J Biol Chem 237:3786-3793

Aviv M, Giladi H, Schreiber G, Oppenheim AB, Glaser G (1994) Expression of the genes coding for the Escherichia coli integration host factor are controlled by growth phase, rpoS, ppGpp and by autoregulation. Mol Microbiol 14:1021-1031 
Baracchini E, Bremer H (1988) Stringent and growth control of rRNA synthesis in Escherichia coli are both mediated by ppGpp. J Biol Chem 263:2597-2602

Barker MM, Gaal T, Gourse RL (2001a) Mechanism of regulation of transcription initiation by ppGpp. II. Models for positive control based on properties of RNAP mutants and competition for RNAP. J Mol Biol 305:689-702

Barker MM, Gaal T, Josaitis CA, Gourse RL (2001b) Mechanism of regulation of transcription initiation by ppGpp. I. Effects of ppG$\mathrm{pp}$ on transcription initiation in vivo and in vitro. J Mol Biol 305:673-688

Bernardo LM, Johansson LU, Solera D, Skarfstad E, Shingler V (2006) The guanosine tetraphosphate (ppGpp) alarmone, DksA and promoter affinity for RNA polymerase in regulation of sigma-dependent transcription. Mol Microbiol 60:749-764

Bernardo LM, Johansson LU, Skarfstad E, Shingler V (2009) Sigma 54-promoter discrimination and regulation by ppGpp and DksA. J Biol Chem 284:828-838

Binns N, Masters M (2002) Expression of the Escherichia coli pcnB gene is translationally limited using an inefficient start codon: a second chromosomal example of translation initiated at AUU. Mol Microbiol 44:1287-1298

Blum E, Carpousis AJ, Higgins CF (1999) Polyadenylation promotes degradation of 3'-structured RNA by the Escherichia coli mRNA degradosome in vitro. J Biol Chem 274:4009-4016

Bougdour A, Gottesman S (2007) ppGpp regulation of RpoS degradation via anti-adaptor protein IraP. Proc Natl Acad Sci USA 104:12896-12901

Brown L, Gentry D, Elliott T, Cashel M (2002) DksA affects ppGpp induction of RpoS at a translational level. J Bacteriol 184:44554465

Cao GJ, Sarkar N (1992) Identification of the gene for an Escherichia coli poly(A) polymerase. Proc Natl Acad Sci USA 89:10380-10384

Costa CS, Pizarro RA, Anton DN (2009) Influence of RpoS, cAMPreceptor protein, and ppGpp on expression of the opgGH operon and osmoregulated periplasmic glucan content of Salmonella enterica serovar Typhimurium. Can J Microbiol 55:1284-1293

Costanzo A, Ades SE (2006) Growth phase-dependent regulation of the extracytoplasmic stress factor, sigma $\mathrm{E}$, by guanosine 3',5' -bispyrophosphate (ppGpp). J Bacteriol 188:4627-4634

Costanzo A, Nicoloff H, Barchinger SE, Banta AB, Gourse RL, Ades SE (2008) ppGpp and DksA likely regulate the activity of the extracytoplasmic stress factor sigma E in Escherichia coli by both direct and indirect mechanisms. Mol Microbiol 67:619-632

Durfee T, Hansen AM, Zhi H, Blattner FR, Jin DJ (2008) Transcription profiling of the stringent response in Escherichia coli. J Bacteriol 190:1084-1096

Eichel J, Chang YY, Riesenberg D, Cronan JE Jr (1999) Effect of ppGpp on Escherichia coli cyclopropane fatty acid synthesis is mediated through the RpoS sigma factor (sigma S). J Bacteriol 181:572-576

Elliott T, Geiduschek EP (1984) Defining a bacteriophage T4 late promoter: absence of a " -35 " region. Cell 36:211-219

Gamer J, Bujard H, Bukau B (1992) Physical interaction between heat shock proteins DnaK, DnaJ, and GrpE and the bacterial heat shock transcription factor sigma 32. Cell 69:833-842

Gentry DR, Hernandez VJ, Nguyen LH, Jensen DB, Cashel M (1993) Synthesis of the stationary-phase sigma factor sigma $\mathrm{S}$ is positively regulated by ppGpp. J Bacteriol 175:7982-7989

Grossman AD, Burgess RR, Walter W, Gross CA (1983) Mutations in the Ion gene of $E$. coli $\mathrm{K} 12$ phenotypically suppress a mutation in the sigma subunit of RNA polymerase. Cell 32:151-159

Harinarayanan R, Murphy H, Cashel M (2008) Synthetic growth phenotypes of Escherichia coli lacking ppGpp and transketolase A $(t k t A)$ are due to ppGpp-mediated transcriptional regulation of tktB. Mol Microbiol 69:882-894
Janaszak A, Majczak W, Nadratowska B, Szalewska-Palasz A, Konopa G, Taylor A (2007) A sigma54-dependent promoter in the regulatory region of the Escherichia coli rpoH gene. Microbiology 153:111-123

Jasiecki J, Wegrzyn G (2003) Growth-rate dependent RNA polyadenylation in Escherichia coli. EMBO Rep 4:172-177

Jasiecki J, Wegrzyn G (2005) Localization of Escherichia coli poly(A) polymerase $\mathrm{I}$ in cellular membrane. Biochem Biophys Res Commun 329:598-602

Jasiecki J, Wegrzyn G (2006a) Phosphorylation of Escherichia coli poly(A) polymerase I and effects of this modification on the enzyme activity. FEMS Microbiol Lett 261:118-122

Jasiecki J, Wegrzyn G (2006b) Transcription start sites in the promoter region of the Escherichia coli pcnB (plasmid copy number) gene coding for poly(A) polymerase I. Plasmid 55:169-172

Jishage M, Ishihama A (1999) Transcriptional organization and in vivo role of the Escherichia coli rsd gene, encoding the regulator of RNA polymerase sigma D. J Bacteriol 181:3768-3776

Joanny G et al (2007) Polyadenylation of a functional mRNA controls gene expression in Escherichia coli. Nucleic Acids Res 35:24942502

Jovanovic G, Rakonjac J, Model P (1999) In vivo and in vitro activities of the Escherichia coli $\sigma^{54}$ transcription activator, $\mathrm{PspF}$, and its DNA-binding mutant, PspF $\Delta$ HTH. J Mol Biol 285:469-483

Kang PJ, Craig EA (1990) Identification and characterization of a new Escherichia coli gene that is a dosage-dependent suppressor of a dnaK deletion mutation. J Bacteriol 172:2055-2064

Kvint K, Farewell A, Nystrom T (2000) RpoS-dependent promoters require guanosine tetraphosphate for induction even in the presence of high levels of sigma S. J Biol Chem 275:1479514798

Lacour S, Kolb A, Landini P (2003) Nucleotides from -16 to -12 determine specific promoter recognition by bacterial $\sigma^{\mathrm{S}}$-RNA polymerase. J Biol Chem 278:37160-37168

Lange R, Hengge-Aronis R (1991) Identification of a central regulator of stationary-phase gene expression in Escherichia coli. Mol Microbiol 5:49-59

Lange R, Fischer D, Hengge-Aronis R (1995) Identification of transcriptional start sites and the role of ppGpp in the expression of rpoS, the structural gene for the sigma S subunit of RNA polymerase in Escherichia coli. J Bacteriol 177:4676-4680

Laurie AD et al (2003) The role of the alarmone (p)ppGpp in sigma $\mathrm{N}$ competition for core RNA polymerase. J Biol Chem 278:14941503

Lemke JJ, Durfee T, Gourse RL (2009) DksA and ppGpp directly regulate transcription of the Escherichia coli flagellar cascade. Mol Microbiol 74:1368-1379

Liebke H, Gross C, Walter W, Burgess R (1980) A new mutation rpoD800, affecting the sigma subunit of $E$. coli RNA polymerase is allelic to two other sigma mutants. Mol Gen Genet 177:277282

Liu JD, Parkinson JS (1989) Genetics and sequence analysis of the pcnB locus, an Escherichia coli gene involved in plasmid copy number control. J Bacteriol 171:1254-1261

Lopilato J, Bortner S, Beckwith J (1986) Mutations in a new chromosomal gene of Escherichia coli $\mathrm{K}-12$, pcnB, reduce plasmid copy number of pBR322 and its derivatives. Mol Gen Genet 205:285290

Lowe PA, Aebi U, Gross C, Burgess RR (1981) In vitro thermal inactivation of a temperature-sensitive sigma subunit mutant (rpoD800) of Escherichia coli RNA polymerase proceeds by aggregation. J Biol Chem 256:2010-2015

Lyzen R, Kochanowska M, Wegrzyn G, Szalewska-Palasz A (2009) Transcription from bacteriophage lambda $\mathrm{pR}$ promoter is regulated independently and antagonistically by DksA and ppGpp. Nucleic Acids Res 37:6655-6664 
Magnusson LU, Farewell A, Nystrom T (2005) ppGpp: a global regulator in Escherichia coli. Trends Microbiol 13:236-242

Magnusson LU, Gummesson B, Joksimovic P, Farewell A, Nystrom T (2007) Identical, independent, and opposing roles of ppGpp and DksA in Escherichia coli. J Bacteriol 189:5193-5202

Merrikh H, Ferrazzoli AE, Lovett ST (2009) Growth phase and (p)ppGpp control of IraD, a regulator of RpoS stability, in Escherichia coli. J Bacteriol 191:7436-7446

Mohanty BK, Kushner SR (2006) The majority of Escherichia coli mRNAs undergo post-transcriptional modification in exponentially growing cells. Nucleic Acids Res 34:5695-5704

Mohanty BK, Maples VF, Kushner SR (2004) The Sm-like protein Hfq regulates polyadenylation dependent mRNA decay in Escherichia coli. Mol Microbiol 54:905-920

O'Hara EB, Chekanova JA, Ingle CA, Kushner ZR, Peters E, Kushner SR (1995) Polyadenylation helps regulate mRNA decay in Escherichia coli. Proc Natl Acad Sci USA 92:1807-1811

Paul BJ et al (2004) DksA: a critical component of the transcription initiation machinery that potentiates the regulation of rRNA promoters by ppGpp and the initiating NTP. Cell 118:311-322

Paul BJ, Berkmen MB, Gourse RL (2005) DksA potentiates direct activation of amino acid promoters by ppGpp. Proc Natl Acad Sci USA 102:7823-7828

Perederina A et al (2004) Regulation through the secondary channelstructural framework for ppGpp-DksA synergism during transcription. Cell 118:297-309

Potamitou A, Neubauer P, Holmgren A, Vlamis-Gardikas A (2002) Expression of Escherichia coli glutaredoxin 2 is mainly regulated by ppGpp and sigma S. J Biol Chem 277:17775-17780

Potrykus K, Cashel M (2008) (p)ppGpp: still magical? Annu Rev Microbiol 62:35-51

Potrykus K, Wegrzyn G, Hernandez VJ (2002) Multiple mechanisms of transcription inhibition by $\mathrm{ppGpp}$ at the lambda $\mathrm{p}(\mathrm{R})$ promoter. J Biol Chem 277:43785-43791

Regnier P, Arraiano CM (2000) Degradation of mRNA in bacteria: emergence of ubiquitous features. Bioessays 22:235-244

Regnier P, Hajnsdorf E (2009) Poly(A)-assisted RNA decay and modulators of RNA stability. Prog Mol Biol Transl Sci 85:137-185

Reichenbach B, Maes A, Kalamorz F, Hajnsdorf E, Görke B (2008) The small RNA GlmY acts upstream of the sRNA GlmZ in the activation of $\operatorname{glm} S$ expression and is subject to regulation by polyadenylation in Escherichia coli. Nucleic Acids Res 36:2570-2580

Sambrook J, Fritsch EF, Maniatis T (1989) Molecular cloning: a laboratory manual. Cold Spring Harbor Laboratory Press, Cold Spring Harbor, NY
Soderbom F, Wagner EG (1998) Degradation pathway of CopA, the antisense RNA that controls replication of plasmid R1. Microbiology 144(Pt 7):1907-1917

Srivatsan A, Wang JD (2008) Control of bacterial transcription, translation and replication by (p)ppGpp. Curr Opin Microbiol 11:100105

Szalewska-Palasz A (2008) Properties of Escherichia coli RNA polymerase from a strain devoid of the stringent response alarmone ppGpp. Acta Biochim Pol 55:317-323

Szalewska-Palasz A, Wrobel B, Wegrzyn G (1998) Rapid degradation of polyadenylated oop RNA. FEBS Lett 432:70-72

Szalewska-Palasz A et al (2007a) Properties of RNA polymerase bypass mutants: implications for the role of ppGpp and its co-factor DksA in controlling transcription dependent on sigma 54. J Biol Chem 282:18046-18056

Szalewska-Palasz A, Wegrzyn G, Wegrzyn A (2007b) Mechanisms of physiological regulation of RNA synthesis in bacteria: new discoveries breaking old schemes. J Appl Genet 48:281-294

Urban JH, Vogel J (2008) Two seemingly homologous noncoding RNAs act hierarchically to activate $g \operatorname{lm} S$ mRNA translation. PLoS Biol 6:e64

Viegas SC, Pfeiffer V, Sittka A, Silva IJ, Vogel J, Arraiano CM (2007) Characterization of the role of ribonucleases in Salmonella small RNA decay. Nucleic Acids Res 35:7651-7664

Vrentas CE et al (2008) Still looking for the magic spot: the crystallographically defined binding site for $\mathrm{ppGpp}$ on RNA polymerase is unlikely to be responsible for rRNA transcription regulation. J Mol Biol 377:551-564

Wigneshweraraj SR et al (2003) Enhancer-dependent transcription by bacterial RNA polymerase: the beta subunit downstream lobe is used by sigma 54 during open promoter complex formation. Methods Enzymol 370:646-657

Wrobel B, Herman-Antosiewicz A, Szalewska-Palasz S, Wegrzyn G (1998) Polyadenylation of oop RNA in the regulation of bacteriophage lambda development. Gene 212:57-65

Wu J, Xie J (2009) Magic spot: (p) ppGpp. J Cell Physiol 220:297-302

Xiao H, Kalman M, Ikehara K, Zemel S, Glaser G, Cashel M (1991) Residual guanosine 3',5'-bispyrophosphate synthetic activity of relA null mutants can be eliminated by spoT null mutations. J Biol Chem 266:5980-5990

Xu F, Cohen SN (1995) RNA degradation in Escherichia coli regulated by $3^{\prime}$ adenylation and $5^{\prime}$ phosphorylation. Nature 374:180 183 